\title{
Formen und Funktionen des Konjunktivs II in historischen ostoberdeutschen Predigten. Eine Langzeit-Perspektive
}

\author{
Simon Pickl (Salzburg)
}

\begin{abstract}
This article presents a diachronic survey of forms and functions of the subjunctive II grammatical category in historical German. The subjunctive II is historically based on the subjunctive preterit form but has lost its temporal function and become a purely modal category. It has developed a variety of synthetic and analytical forms since Old High German, especially in vernacular varieties, but also in Standard German, and fulfils a range of functions, chiefly that of non-affirmativity. The present study aims to shed light on the historical development of the subjunctive II's form and function. Its focus is on East Upper German, and its temporal scope spans over a millennium from the 9th to the 19th century. In order to study the usage and development of the subjunctive II in historical East Upper German sermons, the south-eastern part of SermonC, a diachronic corpus of historical German sermons, is analysed. While this (sub-)corpus is restricted in terms of region and genre, it provides a unique window to written language usage, variation and change in a clearly defined domain over a very long time. The results show that the refunctionalization of the subjunctive preterit as a purely modal category does not date to prehistoric times, as is generally assumed; instead, they point to the 11 th century as the likely time for this change, with limited temporal uses persisting into the 15 th century. The 15th century is also the time when the synthetic subjunctive II form with -et/-at, a typical feature of Bavarian dialects, seems to have emerged in the spoken register. Analytical forms started to appear from the 13th century, and the periphrasis with würde, today accepted in Standard German, prevailed among several written German analytical variants in the 18th century. While Standard German has preserved the distinction between two subjunctive categories, East Upper German spoken language has in effect reduced a two-way morphological system (tense and mood) to a pure mood system, with tense expressed syntactically, in effect refunctionalizing morphological tense as a mood marker.
\end{abstract}

\section{$1 \quad$ Einführung}

Der Konjunktiv II nimmt im heutigen Deutschen als verbale Kategorie insofern eine Sonderstellung ein, als er morphologisch und historisch dem Präteritum nahesteht, funktional jedoch eine eigene modale Kategorie bildet, die für sich genommen tempusneutral ist und für den Ausdruck zeitlicher Verhältnisse auf analytische Mittel angewiesen ist. Über die Umstände der 
Herausbildung seiner verschiedenen Verwendungsweisen im historischen und heutigen Deutsch und des Verlusts seiner temporalen Bedeutungskomponente, die meist in voralthochdeutsche Zeit vermutet wird, ist bislang wenig bekannt.

Es gibt allein im Ostoberdeutschen eine Vielzahl an Varianten, zusätzlich zu den zwei standardsprachlich kodifizierten Bildungsweisen (siehe Kapitel 2.1). Der Konjunktiv II ist damit außerordentlich formenreich und bildet sowohl im synthetischen als auch im analytischen Bereich verschiedene Muster aus, deren Entstehung und Verbreitung im Einzelfall nicht abschließend geklärt ist. Dies betrifft zum einen den im Wesentlichen auf das Mündliche beschränkte synthetischen Konjunktiv-Marker -at, zum anderen die analytischen Formen mit täte bzw. würde als Auxiliar.

In diesem Beitrag wird versucht, auf der Basis eines korpusbasierten Ansatzes die Entwicklung der Formen und Funktionen des Konjunktivs II im Ostoberdeutschen vom 8. bis zum 19. Jahrhundert nachzuzeichnen und einen Beitrag zur Klärung offener Fragen zu leisten. Mit Blick auf die Funktionen des Konjunktivs soll untersucht werden, wie sich der Übergang von der ursprünglichen temporalen (i. e. präteritalen) Verwendungsweise des Konjunktivs Präteritum hin zu seinem tempusneutralen (bzw. präsentischen) Gebrauch vor dem Hintergrund der Entwicklungen im Bereich der einzelnen Funktionen und die Herausbildung des Konjunktivs II als eigenständiger modaler Kategorie in der Geschichte des (Ostober-)Deutschen vollzogen, auch mit Blick auf den Umbau des Tempus-Modus-Systems insgesamt. Hinsichtlich der Form des Konjunktivs werden neben der Dynamik zwischen verschiedenen analytischen Formen des Konjunktivs II auch Entwicklungen im Bereich der synthetischen Formen in den Blick genommen, auch vor dem Hintergrund mögliche Rückschlüsse auf den mündlichen Sprachgebrauch zu ziehen. Dafür wird ein diachrones Predigten-Korpus verwendet, das den Zeitraum vom 9. bis zum 19. Jahrhundert abdeckt und bereits in verschiedenen Studien zum morphosyntaktischen Wandel eingesetzt wurde (z. B. Pickl 2017, 2019, 2020b, 2020c). Aufgrund seiner gleichbleibenden Textsorten- und regionalen Basis eignet es sich besonders gut zur Isolation rein diachroner Dynamiken, erlaubt aber auch wichtige Rückschlüsse auf stilistische Entwicklungen (cf. Pickl 2020b) und auf das Verhältnis von Schriftlichkeit und Mündlichkeit (cf. Pickl 2020c). Der wichtige Aspekt von Sprachkritik, Präskription und Standardisierung kann hier nicht systematisch berücksichtigt werden, spielt jedoch gerade für die jüngeren Entwicklungen eine wichtige Rolle.

Im folgenden Kapitel 2 wird zunächst ein Überblick über verschiedene Formen und Funktionen des Konjunktivs II gegeben, um dann im darauffolgenden Kapitel 3 die Datengrundlage vorzustellen. Kapitel 4 ist der Auswertung des diachronen Korpus unter formalen und funktionalen Gesichtspunkten gewidmet. Kapitel 5 fasst die Ergebnisse zusammen und diskutiert ihre Konsequenzen für die Geschichte des Konjunktivs II im Ostoberdeutschen insgesamt. In Kapitel 6 wird ein kurzes Fazit gezogen sowie ein Ausblick mit Blick auf verbleibende Desiderate gegeben.

\section{Formen und Funktionen des Konjunktivs II}

Der Konjunktiv II wird in morphologischer Hinsicht üblicherweise mit dem Konjunktiv Präteritum gleichgesetzt (cf. Duden-Grammatik 2016: §596; Thieroff 2010: 137). Bei seinen analytischen Varianten tritt diese morphologische Form am entsprechenden periphrastischen Verb 
auf, das die Konjunktiv-II-Bildung zusätzlich lexikalisch markiert. ${ }^{1}$ Die Bezeichnung als Konjunktiv Präteritum ist dabei eine weitgehend historische: Der heutige Konjunktiv II ist formal und funktional aus dem Konjunktiv des Präteritums hervorgegangen. Eine präteritale Funktion weist der Konjunktiv II heute nicht mehr auf (cf. Thieroff 2010: 141), und spätestens seit dem Mittelhochdeutschen ,überwiegt [bei Verben im Konjunktiv] im allgemeinen die Modusaussage, und die zeitliche Bedeutung kann weitgehend aufgehoben sein. Das gilt insbesondere für den Konj. Prät.“ (Paul 2007: 297f.; cf. auch Dal 2014: 173; Klein/Solms/Wegera 2018: 706 sowie Reichmann/Wegera 1993: 419 für das Frühneuhochdeutsche). Von Polenz (2013: 283) spricht hier von der „Detemporalisierung des Konjunktivs Präteritum [...], so dass beide Konjunktive nur noch modal, nicht mehr temporal unterscheidbar sind [...] und nur noch als Konjunktiv I und II bezeichnet werden können“. Schrodt (2004: 131) macht unter Verweis auf Wunderli (1975) generell geltend: „Strukturelles Kennzeichen des Konjunktivs ist [...] die fehlende Tempusgliederung, sie wird als Verzicht auf den sprachlichen Ausdruck der temporaldeiktischen Beziehung zur Sprecherorigo verstanden“ (cf. auch Schrodt/Donhauser 2003: 2507f.). Heute erscheint das formale Präteritum des Konjunktivs refunktionalisiert: „Die beiden einfachen Formen des Konjunktivs, die sich formal an das Präsens und an das Präteritum des Indik. anschließen [...], unterscheiden sich nicht in Bezug auf Tempus, sondern in Bezug auf Modus.“ (Dal 2014: 161) Der Konjunktiv II stellt somit eine eigenständige modale Kategorie dar, die auch vom ursprünglichen Konjunktiv Präteritum abweichende Markierungsformen entwickelt hat. Im Folgenden wird die Bezeichnung Konjunktiv Präteritum ausschließlich mit Bezug auf die morphologische Form verwendet, Konjunktiv II dagegen für die morphosyntaktische Verbkategorie mit ihrer eigenen funktionalen Ausprägung, die im Wesentlichen vom Vergangenheitstempus synchron unabhängig ist.

\subsection{Formen}

Die heutigen Formen des Konjunktivs II gehen demnach im Wesentlichen historisch ursprünglich auf Formen des Konjunktivs Präteritum zurück. ${ }^{2}$ Das gilt jedenfalls für die Formen des Standarddeutschen:

(1) a. ich lebte

b. ich stürbe

c. ich ginge

(2) a. ich würde leben

b. ich würde sterben

c. ich würde gehen

Dabei bilden die synthetischen Konjunktiv-II-Formen (1) zusammen mit den entsprechenden Indikativformen formal ein ausgewogenes Präteritumparadigma, das das des Präsens spiegelt und so den Eindruck eines vollständigen Tempus-Modus-Systems erweckt, wenngleich, wie

\footnotetext{
${ }^{1}$ Auf dialektaler Ebene können Konjunktiv-II-Formen nur teilweise mit Formen des Konjunktivs Präteritum gleichgesetzt werden können. Dies liegt zum einen an der Bildungsweise, die zum Teil durch einen genuinen Konjunktiv-II-Marker (wie - at im Bairischen) erfolgt, und zum anderen am weitgehenden Fehlen einer grammatischen Kategorie Präteritum (wie etwa in den oberdeutschen Dialekten)

2 Für einen Überblick über synchrone Formen des Konjunktivs II im Ostoberdeutschen cf. auch Donhauser (1992); Koch (2019: 294); Lenz (2019: 332, 337); Breuer/Wittibschlager (2020).
} 
oben beschrieben, die grammatischen Tempora im Konjunktiv bloße formale Reflexe einer früheren Tempusunterscheidung darstellen und heute keine temporale Funktion mehr besitzen; hinzu kommt, dass „der Konjunktiv Präteritum insofern eine Randerscheinung dar[stellt], als regelmäßig flektierende Verben im Präteritum keine Modusunterscheidung aufweisen (man lebte, lachte [...]).“ (Duden-Grammatik 2016: 552) Morphologisch gesehen ist der Konjunktiv II also insofern auffällig bzw. peripher, als eine ausgeprägte Asymmetrie zwischen seinen paradigmatischen Bezügen, seiner formalen Markierung und seiner funktionalen Ausrichtung besteht.

Die analytischen Konjunktiv-II-Formen (2) werden mit dem Konjunktiv Präteritum des Hilfsverbs werden und dem Infinitiv des entsprechenden Verbs gebildet. Obwohl die Kategorie Konjunktiv II zusätzlich durch das Hilfsverb werden markiert wird, besteht durch dessen morphologische Form ein formaler Bezug zum Präteritum.

Jenseits des Standarddeutschen werden im bairisch-österreichischen Sprachraum synthetische Formen (auch von starken Verben) mit dem verallgemeinerten Suffix -at der schwachen Verben gebildet, und neben der (hier selteneren; cf. Koch 2019: 294; Breuer/Wittibschlager 2020: 143f.) würde-Periphrase kommt auch eine Periphrase mit dem Konjunktiv Präteritum von tun vor:

(3) a. $i$ lebat

b. $i$ sterbat

c. $i$ gang

(4) a. i tat lebm

b. $i$ tat sterbm

c. $i$ tat ge

In (3) a. bzw. c. wird der Konjunktiv II analog zu (1) a. bzw. b. schwach bzw. stark gebildet; Fälle wie (3) b. stellen dagegen eine Mischform dar, die durch das Antreten des Konjunktiv-IIMarkers -at an den Präsensstamm eines starken Verbs zustande kommt. Formen wie in (3) können deshalb synchron nicht mehr als Varianten des Konjunktivs Präteritum interpretiert werden, erstens, weil die Paradigmen, zu denen sie gehören, im Normalfall kein Präteritum aufweisen, und zweitens, weil das Flexiv - at zwar aus einem ursprünglichen Präteritummarker hervorgegangen ist, aber ausschließlich zur Kennzeichnung des Konjunktivs II geeignet ist. Dabei kann - at auch an für sich genommen bereits vollständige Konjunktiv-II-Formen antreten:

(5) a. i gang

b. $i$ gangat

(6) a. $i$ tat ge

b. $i$ tatat ge

\subsection{Funktionen}

Eine Typologie des Konjunktivs II hinsichtlich seiner Funktion ist vor allem mit Blick auf die Diachronie ungleich schwieriger, während sich der bairische Konjunktiv II vom standarddeutschen funktional kaum unterscheidet (cf. Donhauser 1992). Wie Schrodt (2004: 132) mit Blick auf das Althochdeutsche (cf. auch Erdmann 1874) festhält, ist ,[f]ür die Unterscheidung der Nutzwerte des Konjunktivs [...] jede Feingliederung problematisch, weil man sich fast jede beliebige Gliederung von Nutzwerten vorstellen kann“. Die für die vorliegende Untersuchung 
verwendete Untergliederung lehnt sich teils an die für das heutige Standarddeutsch etablierte Darstellung der Duden-Grammatik (2016: 527-553) an; teils wurde sie auf der Grundlage der Korpusbelege unter Berücksichtigung sprachhistorischer Darstellungen selbst erarbeitet. Fälle, die im vorliegenden Korpus nicht vorkommen, wurden dabei nicht aufgenommen. Die belegten Funktionen gliedern sich in drei Hauptverwendungsweisen, deren Gemeinsamkeit die NichtAffirmativität ist: ${ }^{3}$ 1) eine irreale bzw. potenziale, bei der hypothetische Sachverhalte ausgedrückt werden, deren Nicht-Zutreffen (Irrealis) oder lediglich mögliches Zutreffen (Potenzialis) angenommen wird (ibd.: 528-534), 2) eine indirekte, die bei der Redewiedergabe zum Einsatz kommt (cf. ibd.: 534-548), und 3) eine finale Verwendungsweise, die in Finalsätzen zum Ausdruck von Absichten verwendet wird (ibd.: 548-550), aber heute weitgehend obsolet geworden ist (cf. ibd.: 527). Die indirekte und die finale Verwendungsweise haben gemeinsam, dass hier der Konjunktiv Präteritum mit dem Konjunktiv Präsens wechselt, während in der irrealen/potenzialen Verwendungsweise allein der Konjunktiv II zum Einsatz kommt.

Von diesen Verwendungsweisen zu unterscheiden ist die formseitig mit der würde-Periphrase des Konjunktivs II identische Form der präteritalen Variante des werden-Futurs (cf. ibd.: 512514, 523), bei der formal wurde zu erwarten wäre: ${ }^{4}$

(7) a. Das ist das Haus, in dem ich einmal wohnen werde.

b. Das war das Haus, in dem ich später wohnen würde (statt *wurde).

$\mathrm{Zu}$ den Bezügen zwischen diesem „Futur Präteritum“ und der würde-Periphrase des Konjunktivs II cf. Durrell/Whitt (2016). Da das das präteritale würde-Futur - trotz gewisser funktionaler Bezüge und Überschneidungen - nicht als Funktion des Konjunktivs II gewertet werden kann, wird es in diesem Beitrag nicht näher betrachtet.

Die folgende Aufstellung der Funktionen des Konjunktivs II ist nicht exhaustiv zu verstehen, sondern beschränkt sich auf im Untersuchungskorpus (siehe Kapitel 3) belegte Fälle.

\subsubsection{Funktionsgruppe 1: Irreale und potenziale Verwendungsweisen (eigentlicher Konjunktiv II)}

Die Typen in dieser Hauptgruppe haben gemein, dass sie, zumindest aus heutiger Perspektive betrachtet (Duden-Grammatik 2016: 530-534), ausschließlich in der Präteritumform auftreten und nicht mit dem Konjunktiv Präsens wechseln. Man kann hier also von einem Konjunktiv II im engeren Sinne ausgehen, für den die Tempuszuordnung keine semantische Relevanz besitzt, sondern zur Unterscheidung vom Konjunktiv I dient. Das flexivische Merkmal Konjunktiv Präteritum dient damit zur Markierung des ,eigentlichen“ Konjunktivs II als modaler Kategorie;

\footnotetext{
3 Valentin (1990) spricht von „Nicht-Aktualisation“ (ähnlich z. B. Ágel 2000: 1867f.; Schrodt/Donhauser 2003: 2507).

${ }^{4}$ Laut Durrell/Whitt (2016: 336) ist die Frage, ,,why, if the construction arose to express a future-in-the-past, it should be formed with the preterite subjunctive rather than the preterite indicative of werden to express futurity“", bisher nicht zufriedenstellend geklärt. Sie referieren einige Erklärungsansätze, die hier nicht wiedergegeben werden, von denen jedoch der von Welke (2005) plausibel erscheint; pauschal lässt sich jedoch mit der Duden-Grammatik (2016: 514) sagen, dass es nicht überraschend ist, „dass das Futur zwischen Zukunftsbezug und ,modaler Bedeutung' wechselt [...] und dass die würde-Konstruktion ein ähnlich schillerndes Verhalten zeigt"“.
} 
soll zudem Vergangenheit bzw. Vorzeitigkeit ausgedrückt werden, dienen zur Kodierung von Vorzeitigkeit die zusammengesetzten Vergangenheitstempora (cf. ibd.: 528).

\subsubsection{Irreale Konditionalgefüge (Pro/Apo)}

Die hierher gehörenden Konjunktiv-II-Fälle wurden unterschieden nach Protasis (Pro) und Apodosis (Apo), wobei mit Protasis generell der konditionale Nebensatz gemeint ist, egal, ob er voran- oder nachsteht.

(8) Wenn ich Gottes Herz malen sollte, ich müßte ein unergründliches Meer aller Freuden malen. (OOD_1890_Christenleben_Wür)

Gezählt wurden ebenfalls irreale Konzessivgefüge (,eine Ab- und Umwandlung des irrealen Konditionalgefüges“; ibd.: 531) sowie irreale Aussagesätze ohne explizit formulierte Bedingung, die sich als Quasi-Apodosis mit bloß impliziter Protasis und damit ,als möglich gedachte Folge einer Bedingung, die nicht ausdrücklich in einem Satz formuliert ist" (Reichmann/Wegera 1993: 421) bzw. ,als Teil eines ,verkappten“ irrealen Bedingungsgefüges verstehen“ lassen (Duden-Grammatik 2016: 531).

(9) vnd were yetzt gelegen vnd gebürlich/das ich auch von dem Nachtmal vnfers hern Jefu Chrifti prediget. Nachdē aber in difen tagen brieff von Kay. May. An ein Erbare obrickeit difer Statt zugefchickt worden fein/... (OOD_1535_fride_Nür) ,Und es wäre jetzt passend und angemessen, dass ich auch von dem Nachtmahl unseres Herrn Jesu Christi predigte [wenn nicht folgender Umstand vorläge]. ...

V. a. historisch ist hier außerdem der Typ der irrealen Relativgefüge relevant (cf. auch Valentin 1997: 193; Schrodt/Donhauser 2003: 2514; Dal 2014: 169f.):

(10) Der wêr selig der v̈nserm herren also geantwürten mêcht gegen seiner vrag. (OOD_13.ii_Berlin)

,Derjenige wäre selig, der unserem Herren so auf seine Frage antworten könnte.‘

Fälle wie dieser lassen sich inhaltlich als irreales Konditionalgefüge verstehen bzw. in ein solches umformulieren (z. B. Wenn jemand unserem Herren so auf seine Frage antworten könnte, dann wäre derjenige selig).

\subsubsection{Irreale Wunschsätze (Wunsch)}

Irreale Wunschsätze wurden hier als eigene Kategorie gezählt, lassen sich aber nicht scharf von selbständigen Bedingungssätzen trennen. „Entstanden ist diese Verwendungsweise [...] wohl aus elliptischen Konditionalgefügen, bei denen der Hauptsatz ausgelassen wurde" (DudenGrammatik 2016: 531). ${ }^{5}$ Häufig kommen im Korpus Fälle vor, die als irreale Wunschätze zu verstehen sind, jedoch zusammen mit einem Hauptsatz auftreten und so eine Art irreales Konditionalgefüge bilden:

\footnotetext{
${ }^{5}$ Cf. auch Schönherr (2010: 132); die gegenteilige Ansicht vertritt Behaghel (1928: 638f.); ihm zufolge gehen „[d]erartige Sätze [...] auf selbständige Wunschsätze zurück“; so auch Dal (2014: 173), die darauf hinweist, dass „[d]ie spätere Neubelebung der Form im Deutschen [...] sich vielleicht als Rückbildung aus der hypothetischen Periode" erklären lässt.
} 
(11) ach hett ich etwe gewist, dz dicz also sunt und swer wer gewest und so ser wider got, ya ich hett mich ee $x$ mal lassen todten ee ichs getan hett (OOD_14.ii_Wintz) ,Ach, hätte ich nur gewusst, dass das Sünde und Krankheit ist und so sehr gegen Gott, ja, ich hätte mich eher zehnmal töten lassen, eh ich es getan hätte.

Unterscheiden lassen sich solche Fälle neben der Verwendung partikelhafter Indikatoren wie ach (cf. Dal 2014: 173f.) dadurch von ,regulären“ Konditionalgefügen, dass die Protasis in einem solchen Fall nicht notwendigerweise projizierend wirkt, i. e. auch ohne die Apodosis auskäme.

\subsubsection{Irrealis/Potenzialis mit beschränktem Skopus bei Modalverben (irrMV)}

Hierher gehören Fälle, bei denen der Konjunktiv am Modalverb (bzw. einem dem Modalverb übergeordneten Teil des Verbkomplexes, etwa beim Perfekt) markiert ist, der Skopus der Irrealität des Konjunktivs jedoch auf die vom Modalverb abhängigen Verbteile beschränkt ist und nicht die modale Bedeutung des Modalverbs erfasst:

(12) Kain besser wasser kündet jhr zu rainigung ewres Munds brauchen/als Beichten vnd Betten. (OOD_1577_Liechtmeß_Ing)

„Obwohl die Irrealität bzw. Potenzialität durch die Modusform des Modalverbs ausgedrückt wird, bleibt das Modalverb semantisch gesehen unberührt davon: Die Modalisierung ist ,real', irreal/potenzial ist allein das modalisierte Geschehen (cf. dazu Leirbukt 2008; Lötscher 1991).“ (Duden-Grammatik 2016: 532)

\subsubsection{4 „Höflicher“' Konjunktiv II (höfl)}

Hierunter fallen ,konventionalisierte Verwendungsweisen, die die mit dem normalen Gebrauch des Konjunktivs verbundene irreale/potenziale Unterstellung ausnutzen, um der angesprochenen Person in der Gesprächssituation einen größeren Handlungsspielraum zu verschaffen“ (ibd.: 533). In der vorliegenden Untersuchung tritt dabei weniger der prototypische Fall der höflichen Frage oder Aufforderung auf, sondern die Markierung von Irrealität/Potenzialität an Modalverben wie mögen beim Bezug auf einen Wunsch: 6

(13) bei dem, was ich Jagen möchte (OOD_1847_Heiden_Nür)

\subsubsection{Vergleichssätze (Vergl)}

Der Konjunktiv II bei Vergleichen umfasst diachron sowohl die heutigen irrealen Konstruktionen mit als (ob/wenn) sowie synonymen Varianten (z. B. sam) als auch historisch auftretende, von Komparativen abhängige Nebensätzen mit denn (cf. zu diesem Typ auch Petrova 2008: 94f.; Dal 2014: 173f.), die sich nicht mit einem Konjunktiv übersetzen lassen:

\footnotetext{
${ }^{6}$ Hier sei angemerkt, dass es sich um eine Verwendungsweise des Konjunktivs handelt, die ,sich in dieser Bedeutung so weit verselbstständigt [hat], dass dazu manchmal eine eigene Infinitivform möchten angesetzt wird“ (Duden-Grammatik 2016: 574) - ähnlich, wie wollen bzw. will ursprünglich auf eine Optativ-Form zurückgeht -, sodass man von einem verfestigten Gebrauch des Konjunktivs ausgehen muss. Da jedoch unklar ist, ab welchem Zeitpunkt man von einer solchen Verfestigung ausgehen kann, werden entsprechende Fälle im Korpus als Belege für den Konjunktiv II gewertet.
} 
(14) mit einem wagen der entbran mit geistlichem fiure, also ob er guldin wore.

(OOD_11.ii_Roth)

,... mit einem Wagen, der mit geistlichem Feuer entbrannte, als ob er aus Gold wäre.

(15) sid tu nu bez zera bist. danne du e uuarest (OOD_10.ii_PreSaA) ${ }^{7}$

,... da es dir nun besser geht, als es dir zuvor ging.

\subsubsection{Konsekutivsätze mit Konjunktiv II (Kons)}

Hierher gehören konsekutive Nebensätze ,mit als dass oder mit dass nach zu/nicht so + Adjektiv“ (Duden-Grammatik 2016: 534):

(16) Sie ware viel zu fertig in Nachdencken/als daß Sie sich dem ersten Eindruck der Sinnen häte unterwerfen. (OOD_1751_Elisabetha_Wie)

\subsubsection{Funktionsgruppe 2: Indirekte und finale Verwendungsweisen (uneigentlicher Konjunktiv II)}

Die Verwendungsweisen der Funktionsgruppe 2 haben gemeinsam, dass sie abhängig von der Tempusumgebung mit dem Konjunktiv Präsens wechseln können: Der in der Funktionsgruppe 1 durch die Tempusunterscheidung markierte „Modusunterschied ist [...] aufgehoben“ (Dal 2014: 161) zugunsten einer (passiven) temporalen Bedeutung (historisch), bei der das Präteritum von der temporalen syntaktischen Umgebung abhängig ist, bzw. als Ersatzform für den Konjunktiv I (rezent):

In diesen Sätzen richtete sich das Tempus des Nebensatzverbs ursprünglich in den meisten Fällen, aber nicht ausschließlich, nach dem des Hauptsatzverbs [...]. In der neueren Sprache ist diese Zeitfolgeregel aufgehoben, und damit ist jeder Bedeutungsunterschied der beiden Formen in diesen Verbindungen weggefallen. Die Formen sind jetzt in der Hoch- und Gemeinsprache als bedeutungsgleiche Varianten zu betrachten [...].

Diachron wie synchron ist bei der zweiten Funktionsgruppe demnach nicht von einer selbständigen temporalen Semantik auszugehen, und auch nicht von einer eigenständigen modalen Kategorie (Konjunktiv II) zur Abgrenzung vom modal unterschiedlichen Konjunktiv I. Stattdessen richtet sich das Tempus bei der indirekten Verwendungsweise des Konjunktivs entweder nach der Tempusumgebung oder nach der Frage, ob eine klar als nicht-indikativisch erkennbare Form benötigt wird. Man könnte beim Konjunktiv Präteritum in dieser Funktionsgruppe also von einem „uneigentlichen“ Konjunktiv II sprechen, der formal mit „eigentlichen“ der ersten Funktionsgruppe übereinstimmt, dessen Merkmal Präteritum aber weder zur Markierung von Vergangenheit oder Vorzeitigkeit noch zur Unterscheidung vom Konjunktiv I dient, sondern allenfalls passiv präteritale Bedeutung hat oder bloß eine eindeutigere Formalternative des Konjunktivs I darstellt.

\subsubsection{Indirekte Rede (iR)}

In der indirekten Rede (Duden-Grammatik 2016: 534-548) tritt der Konjunktiv Präteritum (als uneigentlicher Konjunktiv II) diachron gesehen im Wesentlichen in zwei Fällen auf: a) als

\footnotetext{
${ }^{7}$ Der deutsche Konjunktiv uuarest übersetzt hier einen lateinischen Indikativ (fueras).
} 
Ersatz für den Konjunktiv Präsens (wenn dieser mit dem Indikativ Präsens identisch ist (cf. ibd.: 547), aber auch spontan), und b) bedingt durch den präteritalen Kontext (17), i. e. das Tempus richtet sich gemäß der Zeitenfolge nach dem Tempus des übergeordneten Satzes (cf. Reichmann/Wegera 1993: 454; Demske 2019: 78). Letzteres gilt zumindest bis ins Frühneuhochdeutsche, möglicherweise bis ins 19. Jahrhundert (Elspaß 2005: 248). In jedem Fall hat diese Verwendung des Konjunktivs Präteritum nach gängiger Forschungsmeinung keine autonome Tempusbedeutung, wenngleich für das früheste Deutsch möglicherweise c) mit einer ursprünglichen selbständigen Vergangenheitsbedeutung des Konjunktivs Präteritum zu rechnen ist (cf. Erdmann 1874: 26; siehe auch Kapitel 4.1).

(17) Da sie nach Jerusalem kamen, war naturlich ihre erste Frage diese, wo der neugebohrne Konig wäre, dem sie Geschenke zu bringen hätten.

(OOD_1792_Sonntagen_Mün)

\subsubsection{Konjunktiv in Finalsätzen (fin)}

Finale Nebensätze mit Konjunktiv Präteritum (Duden-Grammatik 2016: 549f.) werden hier zum uneigentlichen Konjunktiv II gezählt, da sich hier das Tempus des Konjunktivs im Normalfall nach dem Tempus im übergeordneten Satz richtet (18).

(18) do wolt er sich lazzen besniden, daz der tiuvel iht sein burt erkennet und daz er im sein. $h$. gothait auch vor verburge (OOD_13.ii_Schön6)

,Da wollte er sich beschneiden lassen, damit der Teufel seine Abstammung nicht erkenne und um sein göttliches Wesen vor ihm zu verbergen.

\section{Datengrundlage}

Um die in Kapitel 1 skizzierten Probleme zu beleuchten, i. e. die Entstehung des Konjunktivs II als eigenständige modale Kategorie und die Konsequenzen für das Tempus-Modus-System, die Herausbildung und Entwicklung der analytischen Bildungsweisen sowie die Veränderungen im Bereich der synthetischen Formen, wird in diesem Beitrag eine Korpusuntersuchung durchgeführt, die ein strukturiertes diachrones Predigtenkorpus des Deutschen verwendet. Konkret handelt sich dabei um das ostoberdeutsche Subkorpus (das den bairischen und ostfränkischen Sprachraum umfasst; cf. Hartweg/Wegera 2005: 30f.) des diachronen Predigtenkorpus SermonC, das die Zeit vom 9. bis zum 19. Jahrhundert umfasst und dabei versucht, ein regional möglichst ausgewogenes regionales Verhältnis zu erzielen, was aufgrund der Quellenlage nur für die Zeit ab ca. 1500 durchgängig möglich ist. SemonC orientiert sich strukturell am German Manchester Corpus (GerManC) und dem daran anknüpfenden German Innsbruck Corpus (GermInnC), indem es deren Gliederung sowohl in die fünf Regionen Norddeutsch, Westmitteldeutsch, Ostmitteldeutsch, Westoberdeutsch und Ostoberdeutsch als auch in 50-JahresSchritte sowie deren Struktur von drei Textexzerpten á ca. 2.000 Tokens pro Region und Zeitabschnitt übernimmt. Auch diese Struktur wird nur für die Zeit ab 1500 voll erreicht; für die Zeit davor wurden teilweise auch mehr oder längere Exzerpte verwendet, wo nicht ausreichend Texte vorhanden waren. Das Subkorpus zum Ostoberdeutschen (das auch die Grundlage für Pick1 2020b bildet), besitzt zeitlich die längste Abdeckung: Es enthält Quellen aus dem frühen 9. Jahrhundert sowie ab Mitte des 11. Jahrhunderts eine kontinuierliche Überlieferung. Es umfasst 61 Texte mit insgesamt 106.075 Tokens: 


\begin{tabular}{|c|c|c|c|c|c|c|c|c|c|c|c|c|c|c|c|c|c|c|c|}
\hline \multirow[b]{2}{*}{ 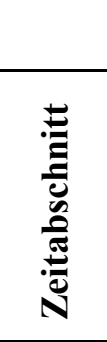 } & \multicolumn{10}{|c|}{ Handschriften } & \multicolumn{8}{|c|}{ Drucke } & \\
\hline & 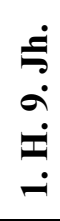 & 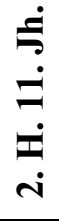 & 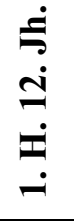 & $\begin{array}{l}\dot{J} \\
\dot{I} \\
\dot{\beth} \\
\dot{\sim}\end{array}$ & $\begin{array}{l}\dot{\Rightarrow} \\
\dot{m} \\
\dot{m} \\
\dot{\square}\end{array}$ & $\begin{array}{l}\dot{\vec{g}} \\
\dot{m} \\
\dot{\vec{\Delta}} \\
\dot{\sim}\end{array}$ & $\begin{array}{l}\dot{\Xi} \\
\dot{ \pm} \\
\dot{I} \\
\dot{\square}\end{array}$ & $\begin{array}{l}\dot{J} \\
\dot{I} \\
\dot{\mathbf{I}} \\
\dot{\mathrm{i}}\end{array}$ & 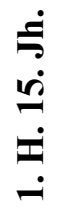 & 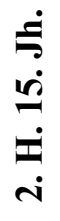 & 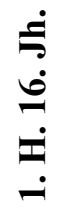 & 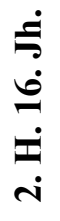 & 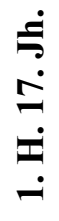 & 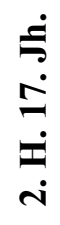 & 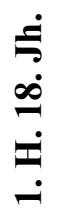 & $\begin{array}{l}\dot{\Delta} \\
\dot{\infty} \\
\dot{0} \\
\dot{\sim} \\
\dot{\sim}\end{array}$ & 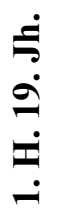 & 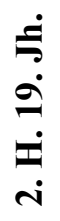 & $\underset{\Xi}{\Xi}$ \\
\hline Texte & 3 & 3 & 4 & 6 & 4 & 5 & 2 & 3 & 4 & 2 & 3 & 3 & 3 & 3 & 3 & 3 & 3 & 3 & 61 \\
\hline 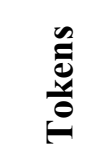 & $\begin{array}{l}\infty \\
\hat{\sigma} \\
i \\
i\end{array}$ & $\begin{array}{l}\infty \\
\underset{\mathbb{U}}{ } \\
\text { i }\end{array}$ & 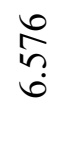 & $\begin{array}{l}+ \\
\stackrel{\infty}{~} \\
\text { ஸे }\end{array}$ & $\begin{array}{l}0 \\
\text { ర్రి } \\
0\end{array}$ & $\frac{\hat{\infty}}{\infty}$ & $\begin{array}{c}\text { No } \\
\stackrel{+}{+} \\
\text { ஸे }\end{array}$ & $\begin{array}{l}\text { D } \\
\text { D. } \\
\text { r }\end{array}$ & $\stackrel{\text { N}}{\stackrel{N}{\sim}}$ & $\underset{\sim}{\stackrel{\infty}{\vec{r}}}$ & $\begin{array}{l}\text { ֶి } \\
\text { ֶु. }\end{array}$ & 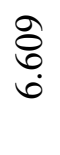 & $\begin{array}{l}\overline{0} \\
\text { ஸె }\end{array}$ & $\begin{array}{l}\text { ๙ै } \\
\text { nे }\end{array}$ & $\begin{array}{l}\mathfrak{n} \\
\stackrel{0}{6}\end{array}$ & $\frac{i}{6}$ & & 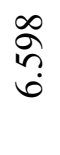 & $\begin{array}{l}\frac{n}{2} \\
\stackrel{0}{0} \\
0\end{array}$ \\
\hline
\end{tabular}

Tabelle 1: Übersicht über das in der vorliegenden Untersuchung verwendete ostoberdeutsche Teilkorpus von SermonC.

Der wesentliche Vorteil dieses Korpus besteht darin, dass damit der Gebrauch des Konjunktivs II im ostoberdeutschen Raum bei minimaler Textsorten- und regionaler Variation über einen sehr langen Zeitraum hinweg untersucht werden kann, was maximale diachrone Vergleichbarkeit gewährleistet. Die Konstanz und relative Stabilität von Predigten in Hinsicht auf ihre Charakteristik als Textsorte und ihre Überlieferung bringt es mit sich, dass die Quellen auch über längere Zeiträume hinweg vergleichbar sind und Verzerrungen des diachronen Wandels durch uneinheitliche Ausschnitte aus der historischen Sprachvariation vermieden werden können (zu dieser Problematik cf. u. a. Kopf 2019; Pick1 2019). Dabei ist jedoch im Blick zu behalten, dass auch die Textsorte Predigten selbst u. a. stilistischem Wandel unterlag (cf. Pickl 2020b, 2020c).

Ein Nachteil dieser Herangehensweise besteht jedoch in dem Umstand, dass der Fokus auf eine Textsorte eine Verengung des Blicks mit sich bringt, wodurch jeweils nur ein kleiner Ausschnitt der Sprachwirklichkeit erfasst werden kann, der für den historischen Sprachgebrauch in einer bestimmten Periode keineswegs repräsentativ ist. Ein solcher Anspruch besteht ausdrücklich nicht, und auch breiter angelegte Korpora könnten allenfalls Anhaltspunkte auf den mündlichen Sprachgebrauch geben; vielmehr geht es darum, in einer auf maximale diachrone Homogenität angelegten Fallstudie grundlegende und möglichst belastbare Einblicke in Wandel und Entwicklung des Konjunktivs II im ostoberdeutschen Raum zu gewinnen. Wie eine textsortenübergreifende Untersuchung zum adnominalen Genitiv in einer kombinierten Untersuchung von GerManC und SermonC jedoch gezeigt hat, können die Predigten für den Schnittbereich beider Korpora von 1650-1800 zumindest für dieses Phänomen durchaus Hinweise auf die Entwicklungen in anderen Textsorten geben (cf. Pickl 2022; zu vergleichbaren Ergebnissen kommen z. B. Durrell 2016, 2017; Kempf 2020, 2021).

\section{$4 \quad$ Auswertung}

Das hier untersuchte Korpus ist aufgrund der durch den großen Zeitraum bedingten sprachlichen Heterogenität nicht getaggt und wurde deshalb manuell ausgewertet. Dabei wurden zunächst alle finiten Verben ermittelt, die sich morphologisch als Formen des Konjunktivs Präteritum bzw. Konjunktivs II einordnen lassen. Die jeweiligen Stellen wurden nach verschiedenen Kriterien kategorisiert. Insgesamt wurden bei der Auswertung 707 Fälle identifiziert, die im Folgenden unter verschiedenen Gesichtspunkten analysiert werden. Dabei geht es zunächst um 
den historischen Verlust der temporalen Komponente des Konjunktivs II und seine Herausbildung als eigenständige modale Kategorie (Kapitel 4.1). Im Anschluss daran wird näher auf seine funktionale Differenzierung eingegangen, auch vor dem Hintergrund ihrer temporalen Strukturierung (Kapitel 4.2), um dann die diachrone Entwicklung der Form des Konjunktivs II, insbesondere seiner analytischen Form, zu beleuchten (Kapitel 4.3).

\subsection{Vom Konjunktiv Präteritum zum Konjunktiv II}

Der Konjunktiv II weist das Präteritum als bloßes morphologisches Merkmal auf, das nicht zur Markierung von Vergangenem oder Vorzeitigem verwendet wird, sondern zusammen mit dem Merkmal Konjunktiv eine eigenständige modale Kategorie mit einem eigenen Funktionsinventar bildet (siehe Kapitel 2). Während laut Schrodt (2004: 131f.) die modale Refunktionalisierung der temporalen Komponente des Konjunktivs Präteritum ,schon vor dem Ahd. eingetreten ist“", geht Demske (2019: 78) davon aus, dass „Konjunktivformen [...] sich im Mittelhochdeutschen [...] noch in Bezug auf das Tempus [unterscheiden] (i. e. consecutio temporum)“, was unter Umständen bis ins 18./19. Jahrhundert nachwirkte (cf. Elspaß 2005: 248; von Polenz 2013: 285). Reichmann/Wegera (1993: 419) halten für das Frühneuhochdeutsche fest, es bestehe meist ,keine Tempusopposition zwischen dem Konj. Präs. und dem Konj. Prät. [...], sondern sie haben in je bestimmten semantischen Umgebungen bestimmte semantische Funktionen“. Auch für das jüngere Deutsch gilt,

that the Subjunctive 2 forms do not have the same time reference as their Indicative counterparts. Whereas the Preterite Indicative has past time reference, the Preterite Subjunctive only occurs with non-past time reference.

(Thieroff 2010: 141)

Als zentrale Eigenschaft des Konjunktivs II ergibt sich daraus die fehlende morphologische Tempusunterscheidung. Dies lässt sich so verstehen, dass die formale Tempusmarkierung beim Konjunktiv nicht zum Ausdruck von Zeitlichkeit in Relation zum Sprechzeitpunkt dient, also keinen eigenen referentiellen Wert besitzt, sondern vielmehr entweder durch den syntaktischen Tempuskontext bedingt ist oder andere Funktionen übernimmt. Beim Konjunktiv II steht das formale Präteritum nicht mehr im Dienst einer Zeitenfolge - und kann nicht einmal in der indirekten Rede für (figurenbezogenen) Vergangenheitsbezug verwendet werden (hierzu dient das analytisch gebildete Perfekt des Konjunktivs), nur als funktionsidentischer Ersatz für den Konjunktiv Präsens -, sondern dient allein der modalen Markierung. Morphologische KonjunktivPräteritum-Formen können also danach unterschieden werden, ob das Präteritummerkmal im Einzelfall (noch) als (passives, i. e. von der Tempusumgebung abhängiges) Tempuskennzeichen oder (schon) als tempusindifferent und damit als Markierung des Konjunktivs II zu werten ist. ${ }^{8}$ Diese Frage ist im Einzelfall keine triviale; in der vorliegenden Untersuchung wird sie deswegen durch die Überprüfung operationalisiert, ob das jeweilige Verb ausgehend von der Sprechzeit eindeutig vergangenheitsbezogen (19)-(20) oder gegenwartsbezogen (21)-(22)

\footnotetext{
${ }^{8}$ Cf. die beiden Funktionen des Präteritums beim Konjunktiv nach Schrodt/Donhauser (2003: 2512): „1. bezeichnet es eine auf einen vergangenen Moment bezogene Vorstellung und hat damit seine gewöhnliche Tempusfunktion, 2. kann diese präteritale Situierung des Geschehens im Sinn einer Tempusmetapher als ausdrückliche Negation der Gültigkeit des Geschehens zum Sprecherzeitpunkt uminterpretiert werden und demnach zu einer eigenständigen Nutzwertgruppe der bedingten Eventualität und Irrealität führen.“
} 
verwendet wird: Liegt mit Blick auf die Sprechzeit ein Vergangenheitsbezug vor, wird die Bedeutung des Konjunktivs Präteritum als (passiv) temporal gewertet (19)-(20); liegt ein Gegenwartsbezug vor, als modal (21)-(22).

(19) Adā uuart kescaffen daz er uuari vooberi des paradysi (OOD_10.II_PreSaB) ,Adam wurde erschaffen, damit er Ackerbauer des Paradieses sei. ${ }^{\circ}$

(20) do sant er zwene siner iunger zv vnserm herren vī hiez in fragen. ob er $x \overline{p c}$ were. oder ob si eines andern solten biten. (OOD_12.ii_Strauch3)

,Da sandte er zwei seiner Jünger zu unserem Herren und ließ sie ihn fragen, ob er Christus sei, oder ob sie nach jemand anderem fragen sollten.

(21) da von mochte wir eu ein michel teil sagen, ob wir die zit heten. (OOD_13.i_Schön1) ,Davon könnten wir euch viel erzählen, wenn wir die Zeit hätten.

(22) Es ist uns, als wenn kein Gott, oder Gott nicht mehr unser Gott wäre. (OOD_1792_Sonntagen_Mün)

Dementsprechend wird im Folgenden zwischen präteritalen und präsentischen Verwendungsweisen des Konjunktivs Präteritum unterschieden. Präteritale Verwendungsweisen des Konjunktivs Präteritum sind solche, bei denen das flexivisch markierte Präteritum in präteritalen Kontexten erscheint (die von einer der Sprechzeit vorausgehenden Referenzzeit geprägt sind) oder temporal bedingt ist und nicht zur funktionalen Markierung der modalen Kategorie „Konjunktiv II" dient. Präsentische Verwendungsweisen sind solche, bei denen das flexivisch markierte Präteritum in präsentischen Kontexten erscheint (die von einer identischen Referenz- und Sprechzeit geprägt sind) oder modal, nicht temporal, bedingt ist und zusammen mit der flexivischen Kategorie Konjunktiv zur funktionalen Markierung der modalen Kategorie „Konjunktiv II“ in Abgrenzung zum Konjunktiv I dient. Auch Fälle, in denen Vorzeitigkeit vor der Sprechzeit durch eine analytische Tempusform ausgedrückt wird (23), werden als präsentisch gewertet, da die Vorzeitigkeit vor der Sprechzeit nicht durch das Präteritummerkmal markiert wird.

(23) hette er sich niht lazzen besniten, so heten die juden gesprochen: (OOD_13.ii_Schön6) ,Hätte er sich nicht beschneiden lassen, dann hätten die Juden gesagt:‘

Abbildung 1 zeigt den diachronen Verlauf präteritaler und präsentischer Verwendungsweisen des Konjunktivs Präteritum basierend auf den oben skizzierten Kriterien. Fälle mit unsicherer Zuordnung wurden entsprechend gesondert markiert. 


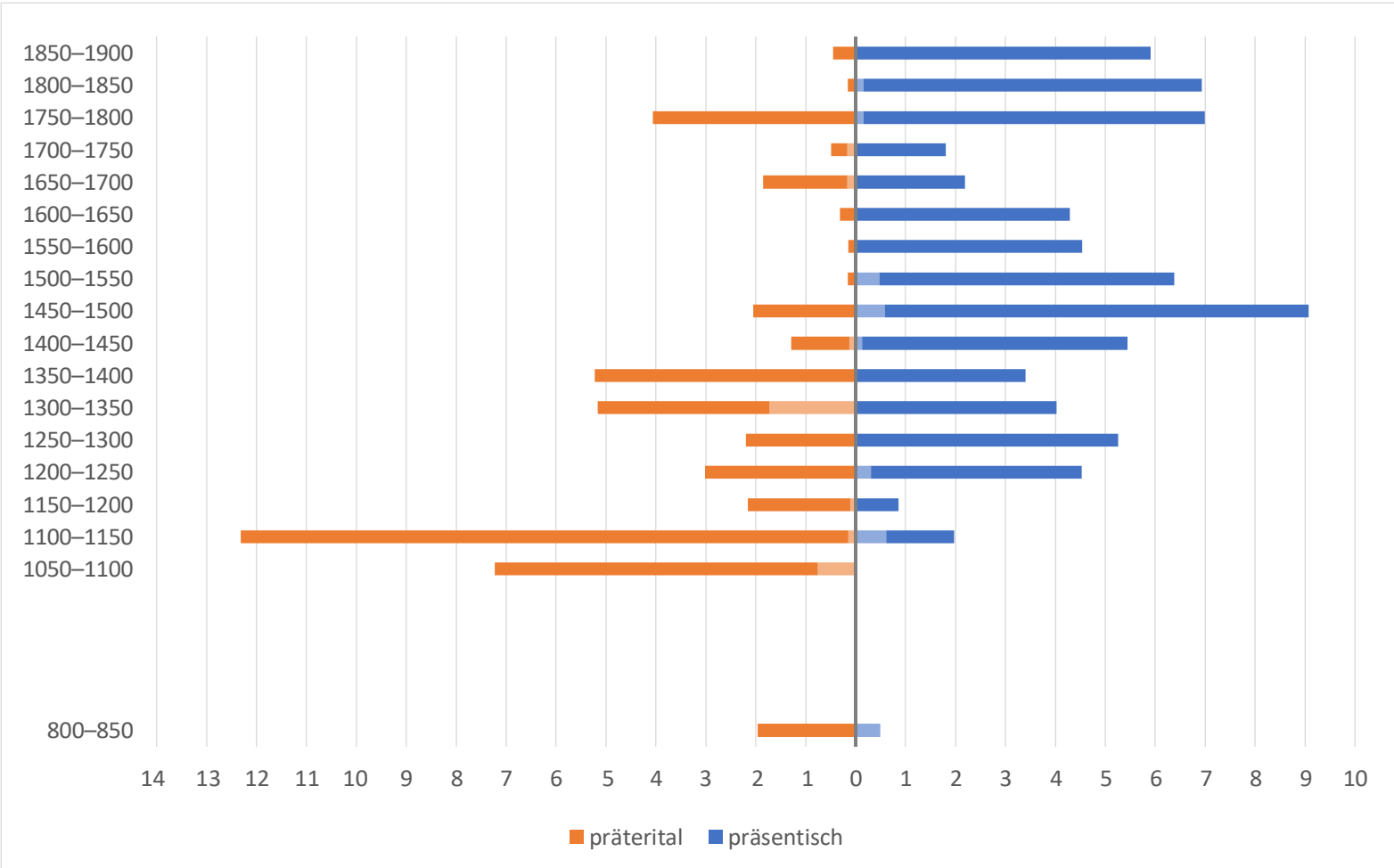

Abbildung 1: Präteritale (orange) und präsentische Verwendungsweisen (blau) des formalen Konjunktivs Präteritum (pro 1.000 Tokens; $N=707$ ). Unsichere Zuordnungen sind heller dargestellt.

Erkennbar ist eine - wenn auch nicht stetige - diachrone Drift von mehrheitlich präteritalen zu vorwiegend präsentischen Verwendungsweisen, die das zunehmende Verblassen der temporalen Komponente des Konjunktivs und damit und seine Etablierung als Konjunktiv II abbildet. Dies spiegelt sich in der Verteilung der einzelnen Funktionen auf die präteritale bzw. präsentische Verwendungsweise, wie im nächsten Kapitel gezeigt wird. Bei den präsentischen Verwendungen des Konjunktivs Präteritum ist in diachroner Hinsicht vor allem auffällig, dass es ab dem 12. Jahrhundert eine mehr oder weniger kontinuierliche Zunahme mit einer Spitze im späten 15. Jahrhundert gibt, gefolgt von einer stetigen Abnahme, die bis ca. 1750 andauert. Danach steigen die Werte sprunghaft an und erreichen fast den Wert des späten 15. Jahrhunderts, was interessanterweise zunächst auch mit einem vorübergehenden Anstieg der bereits praktisch verschwundenen präteritalen Verwendungsweise einhergeht - neben dem Aufkommen von Ersatzformen für den Konjunktiv I um 1800 (cf. Ágel 2000: 1867-1870) möglicherweise auch eine Reaktion auf Gottscheds Befürwortung der „Einhaltung der Zeitenfolge nach lat. Vorbild“ (von Polenz 2013: 285), wie etwa in Beispiel (17). ${ }^{9}$

Bemerkenswert ist, dass es vor 1100 im Korpus keine sicheren Belege für eine präsentische Verwendungsweise gibt. ${ }^{10}$ Dem steht eine bis Mitte des 12. Jahrhunderts im diachronen Vergleich hohe Frequenz präteritaler Verwendungsweisen gegenüber, die darauf hinweist, dass

\footnotetext{
${ }^{9}$ Cf. hierzu auch die Ergebnisse von Elspaß (2005: 248) zu Konjunktivformen in Briefen des 19. Jahrhunderts, denen zufolge möglicherweise ,im 19. Jahrhundert noch das Prinzip der consecutio temporum bei der Wahl der Zeitformen der Indikativ- und Konjunktiv-Endungen nach[wirkte]“.

10 Der einzige (unsichere) Beleg aus OOD_08.i_Exhort_a (daz alle farstantan mahtin ia in hucti cahapen) kann durch die lateinische Vorlage bedingt sein (durch $u t$ bedingter Konjunktiv Imperfekt possent).
} 
Präteritum des Konjunktivs in dieser Zeit noch primär temporal verwendet wurde, während der modal refunktionalisierte Konjunktiv II noch den Ausnahmefall darstellte.

Diese Beleglage ist insofern überraschend, als die präsentische, modal motivierte Verwendungsweise des Konjunktivs Präteritum als gemeingermanisch gilt (cf. Behaghel 1928: 638; Dal 2014: 172-174) und damit von einer Entstehung vor dem Althochdeutschen ausgegangen wird (cf. Schrodt 2004: 131f.). Dies wirft die Frage auf, ob die präsentische Verwendungsweise des Konjunktivs Präteritum im Althochdeutschen möglicherweise weniger etabliert war als bisher angenommen. Diese Frage kann aufgrund der Limitationen der vorliegenden Daten nicht abschließend geklärt werden. Jedoch erweckt ein kursorischer Durchblick der Literaturbelege den Eindruck, dass etwa beim konditional gebrauchten Konjunktiv Präteritum, seinem prototypischen Kontext, im 8. und 9. Jahrhundert bei Isidor und weitgehend bei Otfrid noch eine Tempusdifferenz bestand (cf. auch Erdmann 1874), in der das Präsens für (potenziale) Zustände der Gegenwart stand, das Präteritum für (in der Retrospektive irreale) Zustände der Vergangenheit (cf. etwa die Beispiele in Petrova 2008: 92-95), ${ }^{11}$ während im 11. Jahrhundert bei Notker der Konjunktiv Präteritum bereits klar mit Gegenwartsbezug verwendet wurde (cf. die Beispiele bei Furrer 1971: 74-76), ${ }^{12}$ i. e. die Refunktionalisierung zum tempusindifferenten Irrealismarker vollzog sich vermutlich zwischen dem 9. und dem 11. Jahrhundert. Dies würde sich ungefähr mit dem ersten sicheren Auftreten präsentischer Fälle im vorliegenden Korpus ab 1100 decken. Die wenigen Beispiele in der Literatur, die vor Notker auf eine Verwendung des Konjunktivs Präteritum in Präsenskontexten hinzuweisen scheinen, sind fast ausschließlich übersetzungsabhängig, ${ }^{13}$ i. e. sie geben ein lateinisches Vergangenheitstempus wieder. ${ }^{14}$ Das gilt etwa für das Isidor-Beispiel (73) bei Valentin (1997: 198). ${ }^{15}$ Die dortige Angabe, der irreale Konjunktiv sei im Althochdeutschen ,,immer im Präteritum [gebraucht worden], ohne Rücksicht auf die temporale Situation“, muss in Zweifel gezogen werden, solange klare Belege für die präsentische Verwendung der Präteritumform fehlen. ${ }^{16}$ Regelmäßig belegbar sind diese erst ab Notker; davor gibt es nur isolierte Fälle. ${ }^{17}$ Jedenfalls scheinen sowohl die quantitativen

\footnotetext{
${ }^{11}$ Bei Otfrid zeigen sich erste Ansätze zu einem tempusindifferenten Gebrauch des Konjunktivs (cf. Erdmann 1874: 21-23), wenngleich diese oft eine präteritale Interpretation zulassen und unter dem Einfluss von Metrum und Reim zu stehen scheinen.

12 Ähnliches gilt für andere Funktionen des präsentisch verwendeten Konjunktivs Präteritum, die ebenfalls erstmals bei Notker vorlagenunabhängig auftreten (cf. etwa die Beispiele bei Dal 2014: 172, 174).

${ }^{13}$ Cf. zu dieser generellen Problematik auch Fleischer (2008), Fleischer/Schallert (2011: 37-48).

14 Analoges gilt für die wenigen gotischen Beispiele (cf. z. B. Behaghel 1924: 234-237; Dal 2014: 173f.) und deren griechische Vorlagen.

${ }^{15}$ Ahd. mahti gibt dort ein lateinisches Perfekt wieder.

${ }^{16}$ Interessant ist vor diesem Hintergrund folgende Argumentation bei Dal (2014: 173): „Trotz des spärlichen Vorkommens im Frühgermanischen muss der wünschende Konj. Prät. in vorgeschichtlicher Zeit vorhanden gewesen sein, denn der hypothetische Konjunktiv im konjunktionslosen Bedingungssatz [...] geht wahrscheinlich auf einen wünschenden Konjunktiv im selbständigen Satz zurück. Die Bedeutung der Form entspricht auch genau der des lateinischen wünschenden Konj. Imperfekti, und auch dies scheint auf hohes Alter des Gebrauchs zu deuten.“ Gerade diese Entsprechung mit der lateinischen Form kann jedoch auch ein Hinweis auf Übersetzungsinterferenzen sein. (Zum Verhältnis von wünschendem und hypothetischem Konjunktiv II siehe auch Kapitel 2.2.1.2, insbesondere Fn. 5.)

${ }^{17}$ Mir bekannt sind Ibu christus auur got ni uuari (Isidor III,1; Si christus deus non est), das im Kontext jedoch auch eine präteritale Interpretation zulässt, sowie ih thicho ze dir, thaz unazzer gâbîst dî mir, daz ih mêr ubar tac
} 
Verhältnisse in der vorliegenden Untersuchung als auch die breitere Beleglage darauf hinzudeuten, dass der Konjunktiv Präteritum erst ab dem 11. Jahrhundert regelmäßig präsentisch verwendet wurde; i. e. dass der Konjunktiv II bis zu dieser Zeit als nicht voll grammatikalisiert betrachtet werden kann, sondern gewissermaßen eine uneigentliche, mehr oder weniger spontane Verwendung der Präteritalform darstellte (,im Sinn einer Tempusmetapher“ (Schrodt/Donhauser 2003: 2512) bzw. durch Reinterpretation der grammatischen Form als Ausdruck der Nicht-Affirmativität). ${ }^{18}$ Die Routiniertheit, mit der der lateinische Konjunktiv Imperfekt trotz präsentischem Kontext als deutscher Konjunktiv Präteritum übersetzt wurde, lässt es jedoch wahrscheinlich erscheinen, dass diese Verwendung zumindest bereits eine prinzipiell gangbare Option darstellte. Es stellt sich die Frage, ob die präsentische Verwendung des Konjunktivs Präteritum durch das lateinische Vorbild ausgelöst oder nur begünstigt wurde, oder ob es lediglich zu seiner früheren Sichtbarkeit in althochdeutschen Quellen beigetragen hat. ${ }^{19}$

Folgendes Beispiel aus dem Predigten-Korpus zeigt, dass spätestens im angehenden 12. Jahrhundert der Vergangenheits- bzw. Vorzeitigkeitsbezug, der durch die Refunktionalisierung des Tempus beim Konjunktiv Präteritum verlorenging, durch die Verwendung einer analytischen Tempusform wiederhergestellt wurde (siehe auch (23); Dal 2014: 160f.): ${ }^{20}$

(24) Wan waren sin die iuden innen word, daz si an die ê. swangs ware word, So heten si si gesteinet. (OOD_11.i_ChrGeb)

,Denn wären die Juden dessen gewahr worden, dass sie ohne die Ehe schwanger geworden war, so hätten sie sie gesteinigt.

Dieser Satz steht in präteritalem Kontext (er ne wolde si nivt uermaren geht voraus) und ist aus der Retrospektive klar kontrafaktisch. Das Präteritum dient hier als Irrealis-Marker, während die Vorzeitigkeit der Referenzzeit durch die periphrastische Tempusbildung ausgedrückt wird. Dies war durch die Grammatikalisierung des periphrastischen Perfekts spätestens im 11. Jahrhundert (cf. Fleischer/Schallert 2011: 127f.) möglich geworden. Der reine, synthetische Konjunktiv Präteritum konnte jedoch noch mindestens bis zum Ende des 12. Jahrhunderts im Zusammenhang mit Vergangenheit bzw. Vorzeitigkeit verwendet werden (cf. z. B. die maget antwurte im alsô, daz sî der selben roete von ir herzen toete; aus: Der arme Heinrich, zitiert nach

\footnotetext{
ne liufi hera durstac (Christus und die Samariterin 21-22; gâbîst entspricht einem lateinischen Imperativ, liufi einem lateinischen Konjunktiv Präsens).

18 Grundlage für die Refunktionalisierung der temporalen Komponente als modaler Marker dürfte die Möglichkeit gewesen vergangenheitsbezogene Fälle des Konjunktivs Präteritum als gegenwartsbezogen zu reinterpretieren: Ób ir mih irknúatit . ir sélbon thaz instúantit (Otfrid IV, 15, 23) bedeutet zunächst, Wenn ihr mich erkannt hättet, hättet ihr das verstanden" (präteritale Lesart, die auch durch das marginale cognovissetis (Konj. Plusq.) nahegelegt wird), kann im Kontext (i. e. in derselben Situation) aber auch verstanden werden als ,Wenn ihr mich erkenntet, würdet ihr das verstehen' (präsentische Lesart).

19 Jedoch gilt, dass die „Grenze zwischen Lehn- und Übersetzungssyntax [...] bei nur schriftlich überlieferten Sprachstufen nur schwer zu ziehen [ist]. Bisweilen sind bestimmte Konstruktionen, die in Übersetzungstexten auftreten, in der Zielsprache völlig ausgeschlossen [...]. Es kann aber auch vorkommen, dass in der Sprache vielleicht bereits bestehende strukturelle Anlagen nur verstärkt werden“" (Fleischer/Schallert 2011: 45; cf. auch ibd.: 270-273). Dies scheint uneingeschränkt auch auf die Verwendung des Konjunktivs Präteritum als Irrealis/Potenzialis in präsentischen Kontexten zuzutreffen.

${ }^{20}$ Bei Isidor und Otfrid wäre hier jeweils noch mit rein synthetischen Vergangenheitsformen im Präteritum zu rechnen.
} 
Dal 2014: 160), wobei unter Umständen auch die besonderen Erfordernisse der Reimdichtung zur Bewahrung der älteren Verwendungsweise beitrugen (cf. Fleischer/Schallert 2011: 49-56). Im vorliegenden Korpus geraten entsprechende präteritale Verwendungen im 15. Jahrhundert außer Gebrauch (um später als Ersatzform für den Konjunktiv I wieder zu erscheinen). In dieser Zeit begann der oberdeutsche Präteritumschwund (cf. Schrodt/Donhauser 2003: 2518; Fischer 2018: 391), der den endgültigen Verlust der (passiv) temporalen Bedeutung des Konjunktivs Präteritum - und damit die Notwendigkeit zur analytischen Markierung von Vergangenheit bzw. Vorzeitigkeit - zur Folge hatte und auch im Geschriebenen befördert haben dürfte.

\subsection{Funktionale Differenzierung}

Um die funktionale Entwicklung des Konjunktivs Präteritum im Predigten-Korpus näher zu beleuchten, betrachten wir als Nächstes das diachrone Auftreten der einzelnen Verwendungsweisen (siehe Kapitel 2.2). Die Darstellung erfolgt hier getrennt nach den beiden Funktionsgruppen, die spätestens seit 1100 tendenziell mit den im letzten Kapitel besprochenen temporalen Verwendungsweisen assoziiert sind. Auf die Berücksichtigung unsicherer Zuordnungen wird hier aus Gründen der Übersichtlichkeit verzichtet.

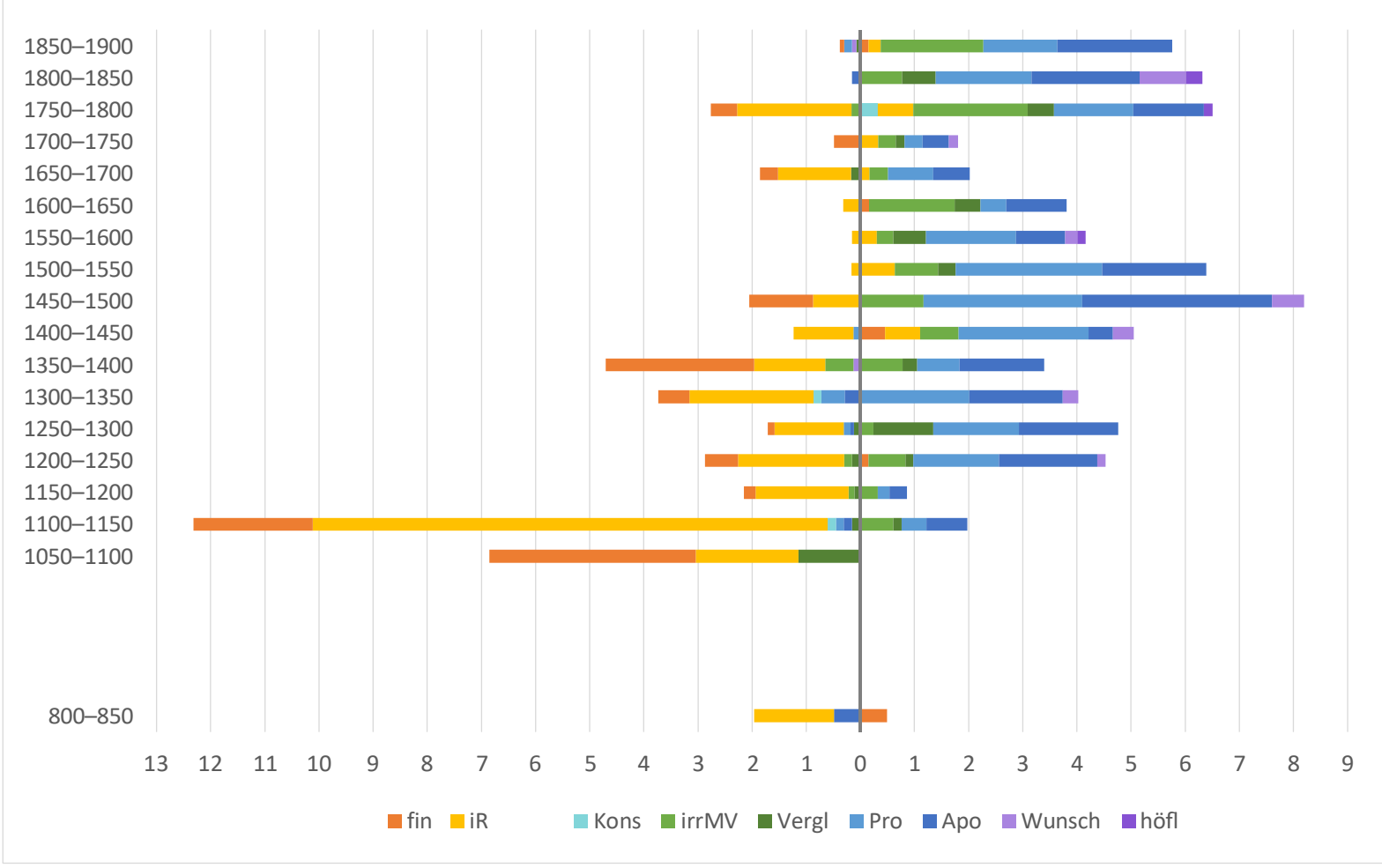

Abbildung 2: Funktionen des formalen Konjunktivs Präteritum (siehe Kapitel 2.2 für die Kürzel) nach präteritaler (links) bzw. präsentischer (rechts) Verwendungsweise (pro 1.000 Tokens; $N=662$ ).

Wie zu sehen ist, treten die Fälle der zweiten Funktionsgruppe (iR und fin; Orange- und Gelbtöne), wie zu erwarten, überwiegend in präteritaler Verwendung auf. Offenbar bestand hier zunächst noch eine Tempusopposition, die es mit sich brachte, dass präteritale Konjunktivformen in präteritalen Kontexten und mit präteritaler Bedeutung (zum Ausdruck einer der Sprechzeit vorausgehenden Referenzzeit) verwendet wurden und in dieser Funktion paradigmatisch mit dem Konjunktiv Präsens wechselten. Dies galt nach Ausweis der Daten in der 
Funktionsgruppe 2 bis ca. 1400 beinahe ${ }^{21}$ uneingeschränkt. Noch heute kann der Konjunktiv Präteritum in Finalsätzen durch ein Vergangenheitstempus im Hauptsatz bedingt sein (cf. Duden-Grammatik 2016: 550). Das Auftreten der ersten präsentischen Verwendungsweisen in diesem Bereich fällt somit ebenfalls in die Zeit des beginnenden Präteritumschwunds (siehe oben), der zum Verlust der Tempusdifferenz in der Funktionsgruppe 2 (zusätzlich) beigetragen haben dürfte. Bemerkenswert ist der annähernde Zusammenbruch beider Funktionen dieser Gruppe zwischen 1500 und 1650 und ihr darauffolgendes Wiederaufleben; jüngere Fälle beider Verwendungsweisen sind womöglich eine Folge der normativen Auseinandersetzung mit dem Konjunktiv durch Bödiker und Gottsched (cf. von Polenz 2013: 285).

Auch bei den Funktionen der Gruppe 1 (Kons, irrMV, Vergl, Pro, Apo, Wunsch, höfl; Grün-, Blau- und Lilatöne) lässt sich eine zunächst nur tendenzielle Festlegung auf eine temporale Verwendungsweise, hier die präsentische, feststellen, die sich ab ca. 1400 deutlich verfestigt (was wiederum in Zusammenhang mit dem Präteritumschwund stehen kann). Auch hier sind die frühesten Belege - bis ca. 1100 - durchweg präterital. Das einzige Beispiel aus dem frühen 9. Jahrhundert für die Kategorie Apodosis (hier im Sinn eines Irrealis mit impliziter Protasis) übersetzt einen lateinischen Konjunktiv Imperfekt (diceret). Die drei Fälle von Vergleichssätzen im 11. Jahrhundert umfassen einen mit sami eingeleiteten irrealen Vergleichssatz sowie zwei (nicht-irreale) mit danne eingeleitete Vergleichssätze. Sowohl bei sami- als auch bei danne-Sätzen wechselt der Konjunktiv Präteritum je nach Tempussituation mit dem Konjunktiv Präsens, wie die Beispiele in Paul (2007: 427f.) zeigen. Erst nach 1100 - und ab da überwiegend - liegen klar präsentische (übersetzungsunabhängige) Verwendungen vor, die auch schon die Verschiebung der Markierung der Temporalität auf die analytische Tempusbildung zeigen (siehe Beispiele (23) und (24)).

Der Entstehung des Konjunktivs II als modale Kategorie kann als Refunktionalisierung der temporalen Komponente des Konjunktivs Präteritum verstanden werden. Die Tempusopposition blieb in der zweiten Funktionsgruppe offenbar länger erhalten als in der ersten, bis etwa 1400. In der Funktionsgruppe 1 ist mit einer solchen Neutralisation freilich schon früher zu rechnen: Hier zeigt sich ein Abbau der temporalen Bedeutung bereits im 12. Jahrhundert, in dem auch die ersten Anzeichen einer „Arbeitsteilung“ zwischen synthetischem Präteritum (als Modusmarker) und analytischen Tempusformen (zur Markierung von Vergangenheit bzw. Vorzeitigkeit) auftreten. Der im Oberdeutschen zuerst auftretende Präteritumschwund (cf. Schrodt/ Donhauser 2003: 2518; Fischer 2018: 391), ein primär mündliches Phänomen, das sich im geschriebenen Deutsch allenfalls quantitativ bemerkbar machte (cf. etwa Fleischer/Schallert 2011: 129-133), hatte offenbar Folgen für die Konsolidierung des Konjunktivs II im Korpus, denn in seine Zeit fällt der endgültige Verlust der Tempusopposition und im Resultat die Festigung des Konjunktivs Präteritum als modale Kategorie. In der Funktionsgruppe 1 hatte dies die Festlegung auf präsentische Verwendungsweisen zur Folge, in der Funktionsgruppe 2 die zunehmend indifferente Verwendung von Präsens- und Präteritumformen des Konjunktivs.

\footnotetext{
${ }^{21}$ Es liegt je ein Beispiel aus dem 9. Jahrhundert (es handelt sich um das oben diskutierte Beispiel aus OOD_08.i_Exhort_a, in dem mahtin lateinischem possent entspricht) und aus der ersten Hälfte des 13. Jahrhunderts vor.
} 


\subsection{Vom synthetischen zum analytischen Konjunktiv II}

Dieser Kapitel befasst sich mit der diachronen Variation zwischen synthetischen und analytischen Formen des Konjunktivs II und dafür relevanten Faktoren sowie mit der Herausbildung der analytischen Form. Als Verben kommen neben dem Konjunktiv von werden in der würdePeriphrase, die seit dem 14. Jahrhundert belegt ist (cf. Reichmann/Wegera 1993: 392; 421; Dal 2014: 175), verschiedene Modalverben vor. Für das Frühneuhochdeutsche ist etwa ,eine Umschreibung mit möchte“ (Reichmann/Wegera 1993: 421) belegt; laut Dal (2014: 175) gibt es im Mittelhochdeutschen „Ansätze“ zu einer periphrastischen Bildung mit verschiedenen Modalverben (cf. auch Paul 2007: 299f.), etwa mit „the pret. subj. of sollen or wollen, the usual future auxiliaries at the time“" (Lockwood 1968: 141; cf. auch Behaghel 1924: 242f.), und Erdmann (1874: 36f.) beschreibt die „Umschreibung [...] durch Hülfsverba“ von beiden Konjunktiven durch eine Reihe von Modalverben bei Otfrid. Diese wohl nicht vollständig grammatikalisierten Periphrasen wurden ,[n] ach der Ausbildung des Futurums mit werden“ (Dal 2014: 175; cf. auch Ágel 2000: 1867) durch die würde-Periphrase verdrängt (cf. auch Reichmann/Wegera 1993: 421), die ,in der mittelhochdeutschen Zeit noch relativ selten [war] und [...] erst mit Beginn der neuhochdeutschen Phase an Verbreitung [gewann]“ (Smirnova 2007: 22). ${ }^{22}$ Historisch und rezent verbreitet, wenn auch standardsprachlich stigmatisiert (cf. Langer 2001; Elspaß 2005: 250; Brooks 2015: 244f.) ist die Verwendung von täte, des Konjunktivs II von tun, als Periphrase (siehe Kapitel 2.1; cf. auch Behaghel 1924: 244).

Die folgende Darstellung betrachtet das Verhältnis zwischen synthetisch und analytisch gebildeten Konjunktiv-II-Bildungen (zunächst ungeachtet der Frage, welches Verb im Einzelfall die Periphrase bildet). Als analytisch werden solche Fälle des Konjunktivs II gewertet, bei denen ein Hilfs- oder Modalverb zur Markierung des Konjunktivs II dient. Die Entscheidung, ob das im Einzelfall zutreffend ist, ist oft nicht eindeutig möglich; als Heuristik hat es sich hilfreich erwiesen, zu prüfen,

a) ob das Hilfs- oder Modalverb (bei flexivisch-synthetischer Markierung des Konjunktivs II am davon abhängigen Verb) ohne Bedeutungsveränderung weglassbar ist oder nicht, und

b) ob die Konstruktion unter Infinitivierung des finiten Verbs und Wahrung des gesamten Verbkomplexes in eine würde-Periphrase überführbar ist oder nicht.

Diese Kriterien gehen davon aus, dass a) eine Periphrase prinzipiell mit ihrer Grundform synonym ist und auf sie zurückgeführt werden kann (z. B. Ich würde singen = Ich sänge) und dass b) eine grammatische Kategorie nicht durch verschachtelte Periphrasen doppelt markiert werden kann (z. B. *Ich würde singen würden, aber Ich würde singen sollen). Bei ihnen ist problematisch, dass es für ihre Anwendung außer der eigenen, gegenwartssprachlich geprägten sprachlichen Intuition und Aspekte der semantischen Kompatibilität keinerlei verlässliche Anhaltspunkte gibt, sodass die Einteilung keine letztendliche Gültigkeit beanspruchen kann,

\footnotetext{
22 Im metasprachlichen sprachkritischen Diskurs des 19. und frühen 20. Jahrhunderts wurde die würde-Periphrase häufig als ein primär österreichisches Phänomen angesehen (cf. Auer 2009: 133-135; Brooks 2015); Auer (2009: 187) argumentiert, dass in Österreich die würde-Periphrase als Ausweichform für die als dialektal stigmatisierte synthetische -ete-Form bei starken Verben verwendet wurde. Schrodt/Donhauser (2003: 2519) sehen sie dagegen gerade als Eigenschaft von nicht-oberdeutschen dialektalen Varietäten an.
} 
wenngleich sie in den meisten Fällen sicher stichhaltig ist. Nicht zu vernachlässigen ist dabei auch die prinzipielle Problematik, dass es sich bei der Herausbildung analytischer Formen um Grammatikalisierungsprozesse handelt, die zwangsläufig mit ambigen Fällen einhergehen. Deswegen wurden Fälle mit unsicherer Zuordnung als solche markiert.

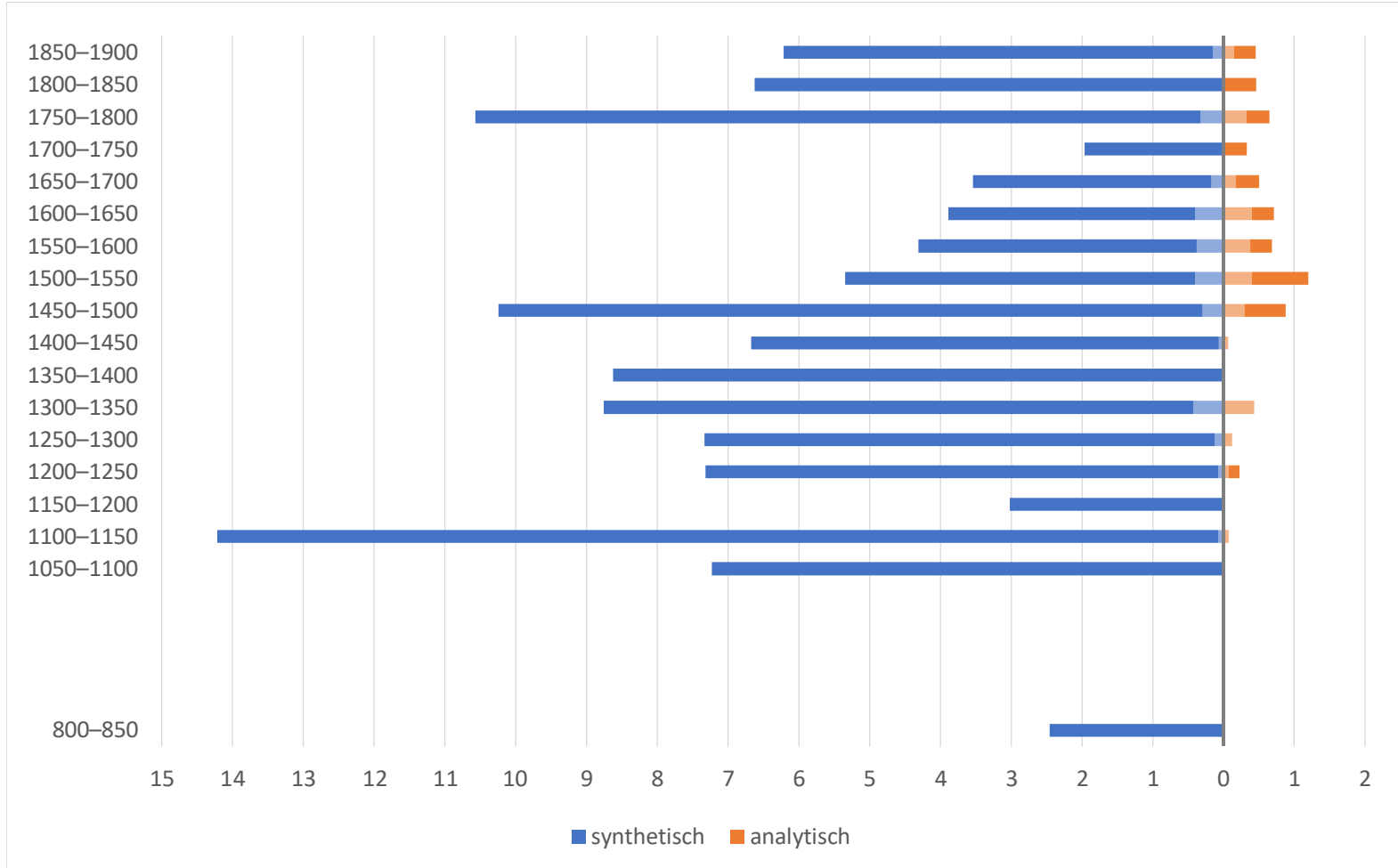

Abbildung 3: Synthetische (blau) und analytische Formen (orange) des Konjunktivs II (pro 1.000 Tokens; $N=$ 707). Unsichere Zuordnungen sind heller dargestellt.

Bei den als potenziell unsicher bzw. ambig eingeordneten Fällen war es vor dem Hintergrund der oben genannten Kriterien nicht möglich, klar zwischen der lexikalischen Bedeutung von Modalverben und rein konjunktivischer Modalbedeutung zu trennen (25), was Ausdruck intrinsischer Ambiguität im Rahmen eines Grammatikalisierungsprozesses sein kann, eine Voraussetzung für das Stattfinden von Reanalyse.

(25) vnd baten si mich vmb daz volch, ich wolt sev nicht erhoeren. (OOD_12.ii_Bair) ,Und bäten sie mich um das Volk, ich wollte/würde sie nicht erhören.

Sicher analytische Fälle treten konsistent erst ab ca. 1450 auf. Auch vorher gab es jedoch mitunter mehr oder weniger eindeutige Beispiele, wie etwa ein Beispiel mit mögen aus der ersten Hälfte des 13. Jahrhunderts zeigt, bei dem potentiale Bedeutung des Modalverbs mögen kaum infrage kommt:

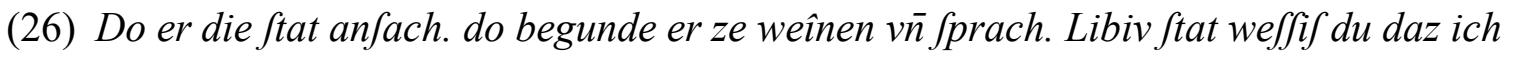
da weîz. du mohtift ouch weînen. (OOD_12.i_Prag)

,Als er die Stadt ansah, da begann er zu weinen und sprach: Liebe Stadt, wüsstest du, was ich weiß, du würdest auch weinen.

Die (potenziell) analytischen Fälle erreichen in der ersten Hälfte des 16. Jahrhunderts ihren Höhepunkt und gehen danach (analog zu den synthetischen Fällen, jedoch etwas stärker als diese) in ihrer Frequenz bis ca. 1750 zurück. Auch anteilig gesehen ist damit seit dem 16./17. 
Jahrhundert ein kontinuierlicher Rückgang der analytischen Bildungsweise bis mindestens Mitte des 19. Jahrhunderts (von potenziell bis zu $28 \%$ (inkl. unsicherer Fälle) auf ca. $6 \%$ ) zu verzeichnen. Die Zeitspanne, in der der Anteil analytischer Formen beständig 10\% und mehr beträgt, i. e. ca. 1450-1750, deckt sich in etwa mit der Phase des Kanzleistils, der sich in dieser Zeit auch in Predigten bemerkbar machte (cf. Pick1 2020b, 2022), sodass vermutet werden kann, dass die komplexere, ,,aufwändigere“" periphrastische Bildungsweise in dieser Zeit als prestigeträchtiger empfunden wurde. ${ }^{23}$

Im Hinblick auf die funktionale Verteilung zwischen synthetischem und analytischem Konjunktiv II zeigt sich, dass fast alle Fälle von potenziellen analytischen Formen in hypothetischen Gefügen vorkommen: Nur ein Fall kommt im frühen 12. Jahrhundert für eine Vergleichskonstruktion vor (hier kommt auch futurische Bedeutung des Hilfsverbs infrage) und je ein Fall im frühen 16. Jahrhundert und im frühen 17. Jahrhundert, ebenfalls in Vergleichskonstruktionen. Alle übrigen Fälle verteilen sich auf Protasis und Apodosis. Bei der Verteilung zwischen diesen beiden Funktionen zeigen sich Unterschiede zwischen den verwendeten Periphraseverben.

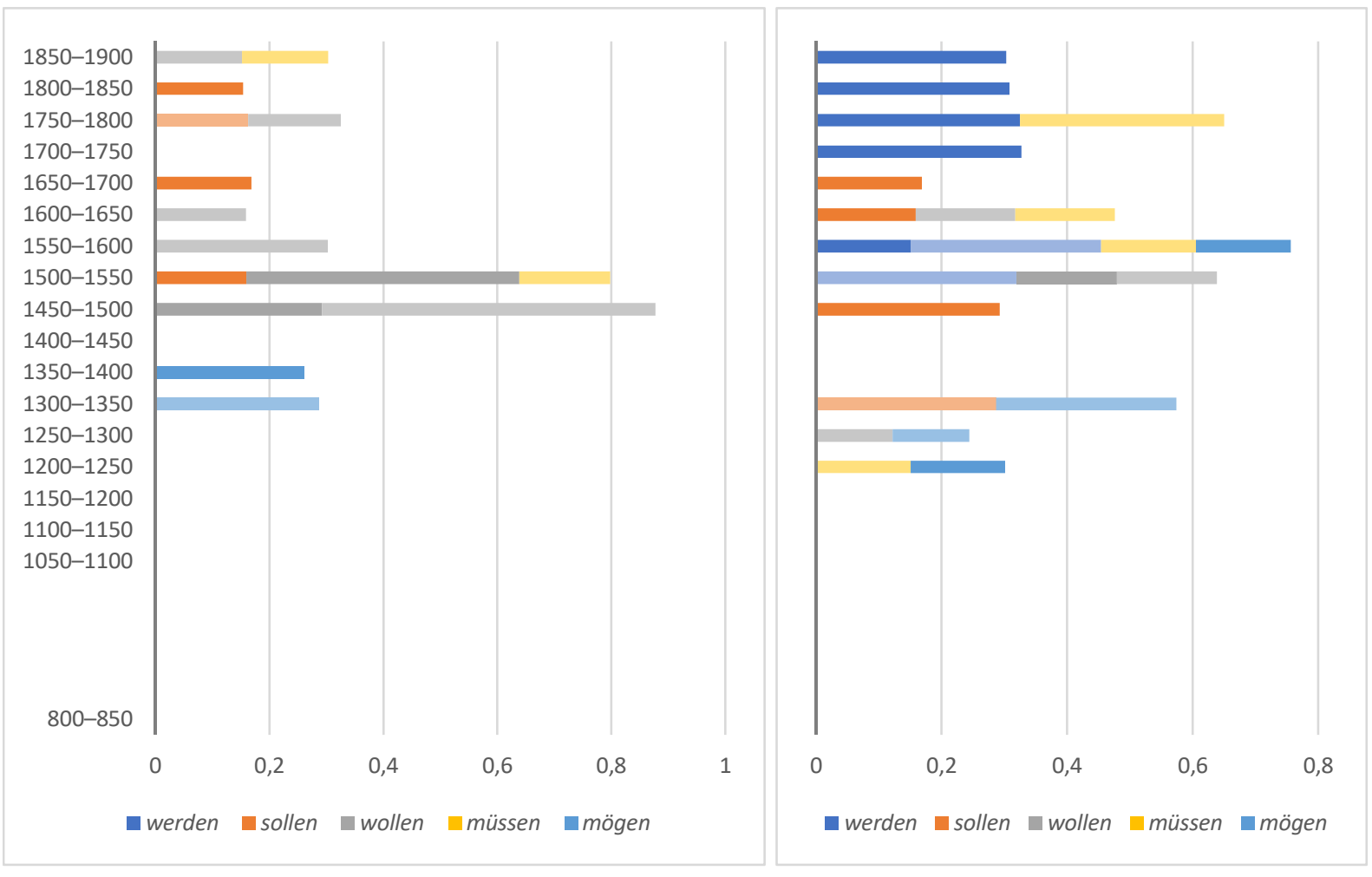

Abbildung 4: Verbperiphrasen bei potenziell analytischen Fällen (pro 1.000 Tokens) in der Protasis (links; $N=19)$ und der Apodosis (rechts; $N=50$ ). Unsichere Zuordnungen sind heller dargestellt.

Die ersten Kandidaten für analytische Formen kommen im Mittelhochdeutschen vor, wobei unterschiedliche Modalverben beteiligt sein können. Weitgehend auf das Mittelhochdeutsche und frühe Frühneuhochdeutsche beschränkt ist die Periphrase mit mögen bzw. möchte (cf. auch Reichmann/Wegera 1993: 421), sowohl in der Protasis als auch in der Apodosis. Nach 1400 kommt sie im vorliegenden Korpus nur einmal in der zweiten Hälfte des 16. Jahrhunderts, in

\footnotetext{
23 In diese Richtung weisen auch die Ergebnisse aus Durrell/Whitt (2016): Hier kommt die würde-Konstruktion im Zeitraum 1650-1800 zu Beginn besonders häufig in Rechtstexten vor und geht dort - parallel zur Aufgabe des Kanzleistils insgesamt - bis zum Ende des 18. Jahrhunderts zurück.
} 
der Apodosis, vor. Vergleichsweise häufig ist die Konjunktiv-II-Bildung mit wollen. Es tritt besonders im Frühneuhochdeutschen ab 1450 auf, in der Protasis jedoch potenziell noch im 19. Jahrhundert. Es zeigt insgesamt eine Präferenz für diesen Kontext, kommt aber auch in der Apodosis vor. Es gibt einige Hinweise auf potenzielle Periphrasen mit müssen; diese sind jedoch relativ spärlich, nicht auf eine bestimmte Periode beschränkt und zeigen allenfalls eine leichte Tendenz zur der Apodosis. Sollen erscheint sowohl in der Protasis als auch in der Apodosis. Um 1800 könnte sich die Entwicklung hin zu konditionalem sollen andeuten, wie es heute häufig in uneingeleiteten, potenzialen Konditionalsätzen (cf. auch Durrell/Whitt 2016: 350; Zifonun/Hoffmann/Strecker 1997: 1893f.) verwendet wird (ganz analog zu englischem should in dieser Position). Weiterhin zeigt sich, dass in diesem Korpus die würde-Periphrase, die hier seit dem 16. Jahrhundert auftritt (cf. von Polenz 2021: 47), ausschließlich auf die Apodosis beschränkt ist. Diese Verteilung entspricht dem traditionellen präskriptiven Standpunkt, der seit dem 19. Jahrhundert belegbar ist (cf. Durrell 2007), und passt außerdem zu der vergleichbaren diachron festgestellten Tendenz, nach der die würde-Periphrase ,,meist in Hauptsätzen, seltener in bedingenden Nebensätzen“ (Reichmann/Wegera 1993: 421 für das Mittelhochdeutsche; cf. auch Behaghel 1924: 245; Smirnova 2006: 45) auftrat. Die Tendenz der würde-Periphrase zur Apodosis ist im Forschungskontext weniger klar ausgeprägt als im vorliegenden Korpus; bei Durrell/Whitts (2016: 348f.) Untersuchung auf der Grundlage von GerManC (1650-1800) kommen etwa $64 \%$ aller Fälle in Konditionalgefügen in der Apodosis vor. ${ }^{24}$ Wie die vorliegenden Daten belegen, ist die Distribution zwischen der Protasis und der Apodosis nicht das Resultat von Präskription, denn die Verteilung der Periphrase nimmt - zumindest hier - die spätere Präskription bereits deutlich vorweg (cf. auch Durrell/Whitt 2016). ${ }^{25}$

Bemerkenswerterweise ist die Umschreibung mit täte im Korpus überhaupt nicht belegt: Tun im Konjunktiv Präteritum kommt durchaus als Vollverb vor, nicht jedoch als Hilfsverb einer Periphrase. Dies kann auf zweierlei hindeuten: Entweder wurde täte erst zur analytischen Markierung des Konjunktivs - als konjunktivische Variante der tun-Periphrase - verwendet, nachdem diese im Geschriebenen stigmatisiert wurde (ein Prozess, der sich über mehrere Stufen ab dem 17. Jahrhundert nachzeichnen lässt; cf. Langer 2001: 176-213), oder der täte-Konjunktiv war stets ein primär konzeptionell mündliches Merkmal. ${ }^{26}$ Letzteres wäre vor allem dann plausibel, wenn er sich zu einer Zeit etabliert hätte, in der das Varietätenspektrum bereits klar zwischen Schriftlichkeit und Mündlichkeit polarisiert war (i. e. jedenfalls nach 1400; cf. Pick1 2020c). ${ }^{27}$

\footnotetext{
${ }^{24}$ Interessanterweise ist diese Tendenz in GerManC laut Durrell/Whitt (2016: 348-349) vor 1700 noch umgekehrt (mit nur $37 \%$ der würde-Periphrasen in der Apodosis), wofür offenbar zum großen Teil ,the striking extent of the use of the würde-construction in the protasis in legal texts“ verantwortlich ist, wenngleich ,after 1700 there is a marked decline in the use of würde in the protasis in all registers".

${ }^{25} \mathrm{Im}$ Gegenteil zeigt Brooks (2015: 247f.) auf der Basis von Szatzkers (2002) Zahlen, dass die Stigmatisierung der Periphrase eher eine Reaktion auf ihre Ausbreitung auf neue Kontexte war (Smirnovas (2007) „Phase III“ der Grammatikalisierung von würde + Infinitiv).

${ }^{26}$ Entsprechend häufiger tritt die täte-Periphrase in (tendenziell mündlicheren) Briefen des 19. Jahrhunderts auf cf. Elspaß 2005: 243-267).

${ }^{27}$ Langer (2001: 78f.) findet vier Beispiele in einer Predigt (Wien, 1680) Abraham a Sancta Claras (der freilich für seinen eigenwilligen Stil bekannt war) und vereinzelte Belege aus anderen Regionen und Textsorten, die (mit
} 
Der quantitative Anstieg aufseiten der analytischen Bildungsweise Mitte des 15. Jahrhunderts - zusammen mit dem erstmaligen Auftreten sicherer Fälle - legt wiederum einen möglichen Zusammenhang mit dem in dieser Zeit verstärkten Präteritumschwund (cf. Fleischer/Schallert 2011: 129-133) nahe, zumal die Konjunktivperiphrase in den Kontext einer allgemeineren Tendenz zur analytischen Bildungsweise zu stellen ist (cf. Nübling et al.: 329-343), im Zuge derer grammatische und lexikalische Information zwischen finiten und infiniten Bestandteilen aufgeteilt wurden. Mit dem Verlust des Präteritums als morphologischer Tempuskategorie im Gesprochenen war es wahrscheinlich, dass auch im Geschriebenen synthetische Präteritumformen seltener gebildet wurden und damit auch die entsprechenden Konjunktivformen, die bei starken Verben ,von vielen heute als gehobener oder archaischer Sprachgebrauch empfunden werden oder überhaupt nicht mehr bekannt sind“" (Elspaß 2005: 246; cf. auch 249f.), ${ }^{28}$ sodass häufiger auf analytische Bildungen ausgewichen wurde. Eine mögliche Motivation für einen solchen Vorgang wäre die einfachere Bildung von analytischen Konjunktiven gegenüber deren „schwieriger“ zu bildenden synthetischen Alternativen (von Polenz 2021: 179 spricht von einer „Unsicherheit im Konjunktivgebrauch“), die gerade bei starken Verben die mentale Aktivierung vom Präsensstamm abweichender und nicht ohne Weiteres ableitbarer Formen erfordern - ein Effekt, der wohl gerade mit zunehmender Standardisierung an Relevanz gewann. Eine solche „Vermeidungsstrategie“ wird sogar ,,in grammatischen Leitfäden des 19. Jahrhunderts als übliches Verfahren beschrieben“" (Elspaß 2005: 250) und ist in erster Linie bei starken Verben zu erwarten. Dagegen ist die übliche Begründung für die zunehmende Bevorzugung analytischer Formen im Forschungsdiskurs jedoch die Tendenz zur Vermeidung uneindeutiger Formen, die unzureichend zwischen Indikativ und Konjunktiv Präteritum unterscheiden (cf. etwa Behaghel 1924: 243f.; Lockwood 1968: 141; Smirnova 2006: 44f.), was vor allem bei schwachen Verben vorkommt, nicht die Tendenz zur Vermeidung schwieriger oder unbekannter unregelmäßiger Formen.

Die möglichen Ursachen seien hier als zwei Hypothesen - zusammen mit den jeweils zu erwartenden Verteilungen der Formen über Verbtypen - formuliert:

1. Auf analytische Formen wurde besonders dann ausgewichen, wenn die synthetische Form nicht zuverlässig gebildet werden konnte. Dies war der Fall bei unregelmäßigen Verben, bei denen der Konjunktiv II weder mittels einfacher Strukturregeln aus frequenteren Formen wie dem Infinitiv ableitbar noch als Ganzes aus dem Gedächtnis abrufbar war. Dies wäre gerade im Kontext des oberdeutschen Präteritumschwundes plausibel (cf. Auer 2022). Besonders häufig sollten demzufolge v. a. starke Konjunktiv-II-Formen durch analytische Bildungen ersetzt werden.

2. Analytische Formen wurden v. a. deshalb gebildet, um den Konjunktiv II eindeutig zu kennzeichnen. Dies betrifft in erster Linie diejenigen Verben, deren Konjunktiv-II-Formen sich nicht (ausreichend) von Indikativformen unterscheiden, und ist nicht auf Regionen mit Präteritumschwund beschränkt. Dazu zählen v. a. schwache Verben (cf. Breuer/Wittibschlager 2020: 154), aber auch - v. a. bei eingetretener Apokope - starke

einer Ausnahme aus dem Niederdeutschen) aus dem 15. bis 18. Jahrhundert stammen. Dies deutet klar in Richtung der zweiten Hypothese.

28 „Wo die Schriftsprache noch einfache Formen hat, sind es wohl archaische Weiterführungen älteren Sprachgebrauchs; zum Teil sogar bewußte, denn in neuerer Zeit wird vielfach in grammatischen Anweisungen die unumschriebene Form dringend empfohlen.“(Behaghel 1924: 244) 
Verben der Ablautreihen I oder VII, deren Präteritalformen nicht umlautfähig sind (cf. auch Fleischer/Schallert 2011: 141).

Um zu überprüfen, welche der beiden potenziellen Mechanismen für die Tendenz zur Periphrase verantwortlich zu machen ist, werden im Folgenden die Verteilungen der Konjunktiv-IIFormen abhängig von verschiedenen Verbtypen verglichen. Da analytische Bildungsweisen auf Konditionalsätze sowie auf Vergleichssätze beschränkt sind, werden hierfür nur diese Funktionen betrachtet. Dazu werden zunächst die hochfrequenten Verben sein, haben und tun sowie Modalverben in den Blick genommen. Modalverben $(N=60)$ bilden im Korpus überhaupt keine analytischen Konjunktive aus (interessanterweise obwohl gerade bei sollen und wollen kein Unterschied zwischen den Indikativ- und Konjunktivformen besteht), ${ }^{29}$ dasselbe gilt für werden $(N=15)$. Das Verb tun $(N=8)$ kommt nur einmal, im 16. Jahrhundert, in einem potenziell analytischen Konjunktiv vor. Konjunktive von sein und haben (siehe Abbildung 5) kommen dagegen ab dem 17. bzw 18. Jahrhundert auch, wenngleich selten, analytisch gebildet vor (mit einem potenziellen Vorläufer eines analytischen Konjunktivs bei sein im 14. Jahrhundert).

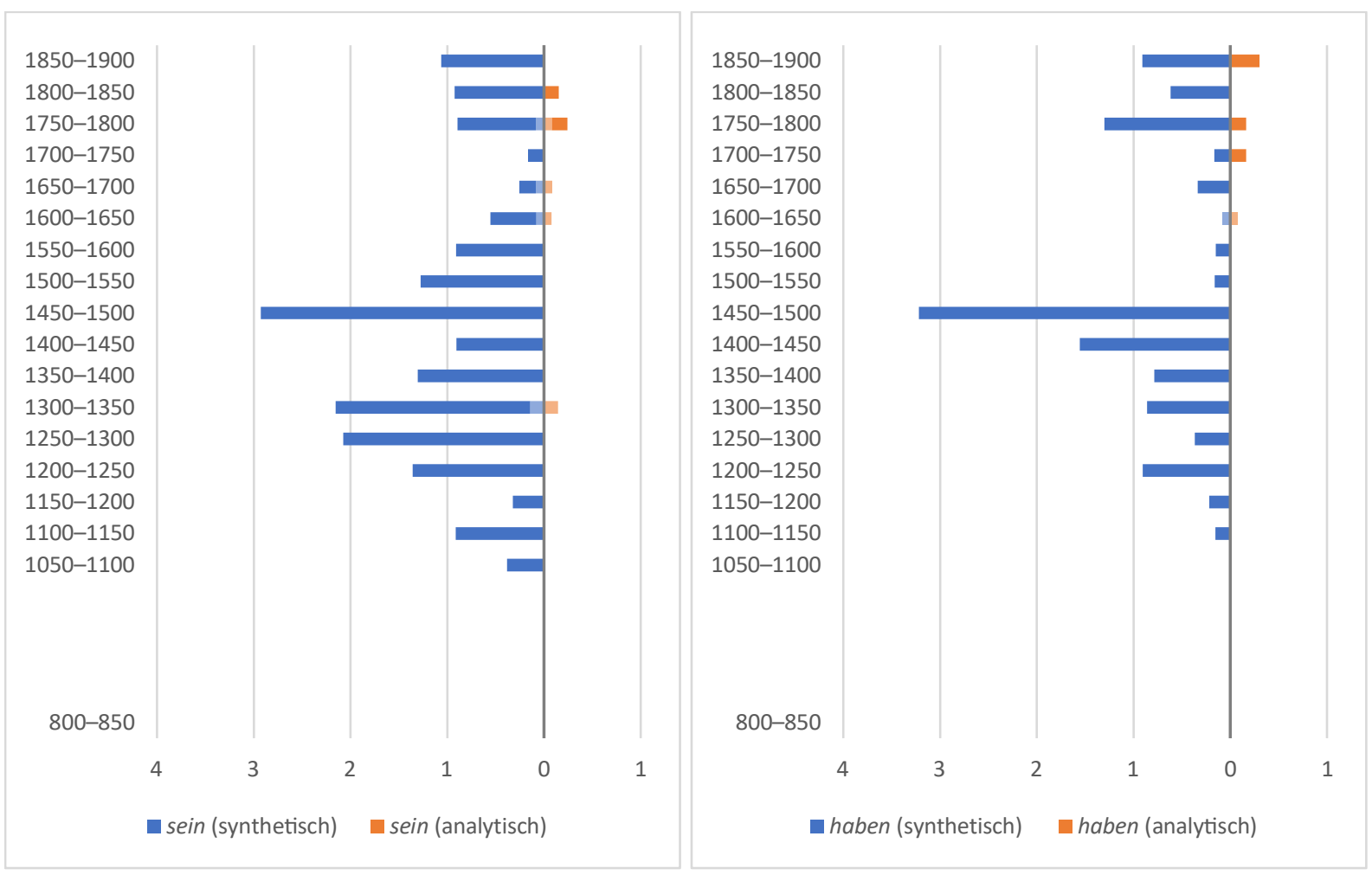

Abbildung 5: Synthetische (blau) und analytische Formen (orange) des Konjunktivs II der Verben sein (links; $N=107$ ) und haben (rechts; $N=68$ ) in Konditional- und Vergleichssätzen (pro 1.000 Tokens).

Abbildung 6 zeigt die Verteilung von synthetischen und analytischen Konjunktiv-II-Formen bei starken und schwachen Verben. ${ }^{30}$ Die analytische Bildungsweise tritt hier deutlich früher auf als bei sein und haben (cf. Abbildung 5), wobei eine Rolle spielen dürfte, dass diese hochfrequent sind und häufig selbst als Auxiliare fungieren. Es sind insgesamt keine starken Unterschiede zwischen starken und schwachen Verben zu erkennen, letztere neigen jedoch etwas

29 „Die zähe Ausdauer dieser einfachen Konjunktive erklärt sich im allgemeinen aus ihrer Häufigkeit““ (Behaghel 1924: 245).

${ }^{30}$ Abbildung 6 und Abbildung 7 umfassen nicht die bereits besprochenen hochfrequenten Verben. 
früher und deutlicher $\mathrm{zu}$ analytischen Formen als erstere, was gegen die erste Hypothese spricht; auch bei letzteren ist jedoch v. a. vom 15. bis zum 17. Jahrhundert eine ausgeprägte Tendenz zu analytischen Formen feststellbar. Vergleicht man stattdessen Verben mit distinkten Konjunktiv-II-Formen mit solchen mit indistinkten (Abbildung 7), ${ }^{31}$ zeigt sich, wie zu erwarten, ein sehr ähnliches, und kein wesentlich klareres Bild: Auch hier gibt es keine deutlichen Unterschiede zwischen den beiden Typen. ${ }^{32}$ Damit lässt sich keine der beiden Hypothesen erhärten.

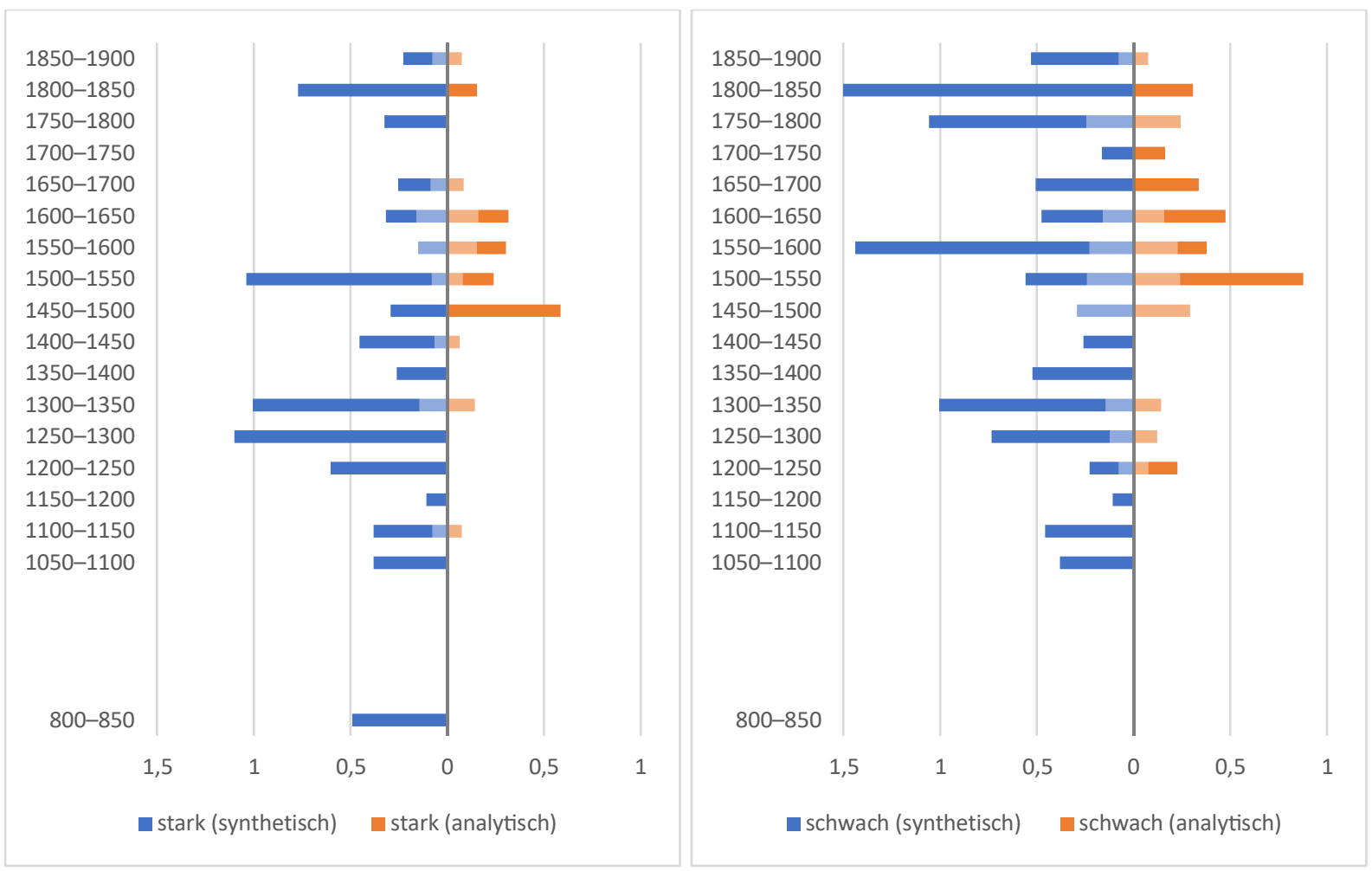

Abbildung 6: Synthetische (blau) und analytische Formen (orange) des Konjunktivs II von starken (links; $N=56$ ) und schwachen Verben (rechts; $N=80$ ) in Konditional- sowie Vergleichssätzen (pro 1.000 Tokens).

\footnotetext{
${ }^{31}$ Als indistinkt wurden Formen gewertet, bei denen Indikativ und Konjunktiv Präteritum dieselbe Stammform aufweisen, ungeachtet ihrer Verbklasse.

${ }^{32}$ Szatzker (2002) und Durrell/Whitt (2016: 357f.) können mit ihren Daten ebenfalls keine entsprechende Tendenz feststellen.
} 


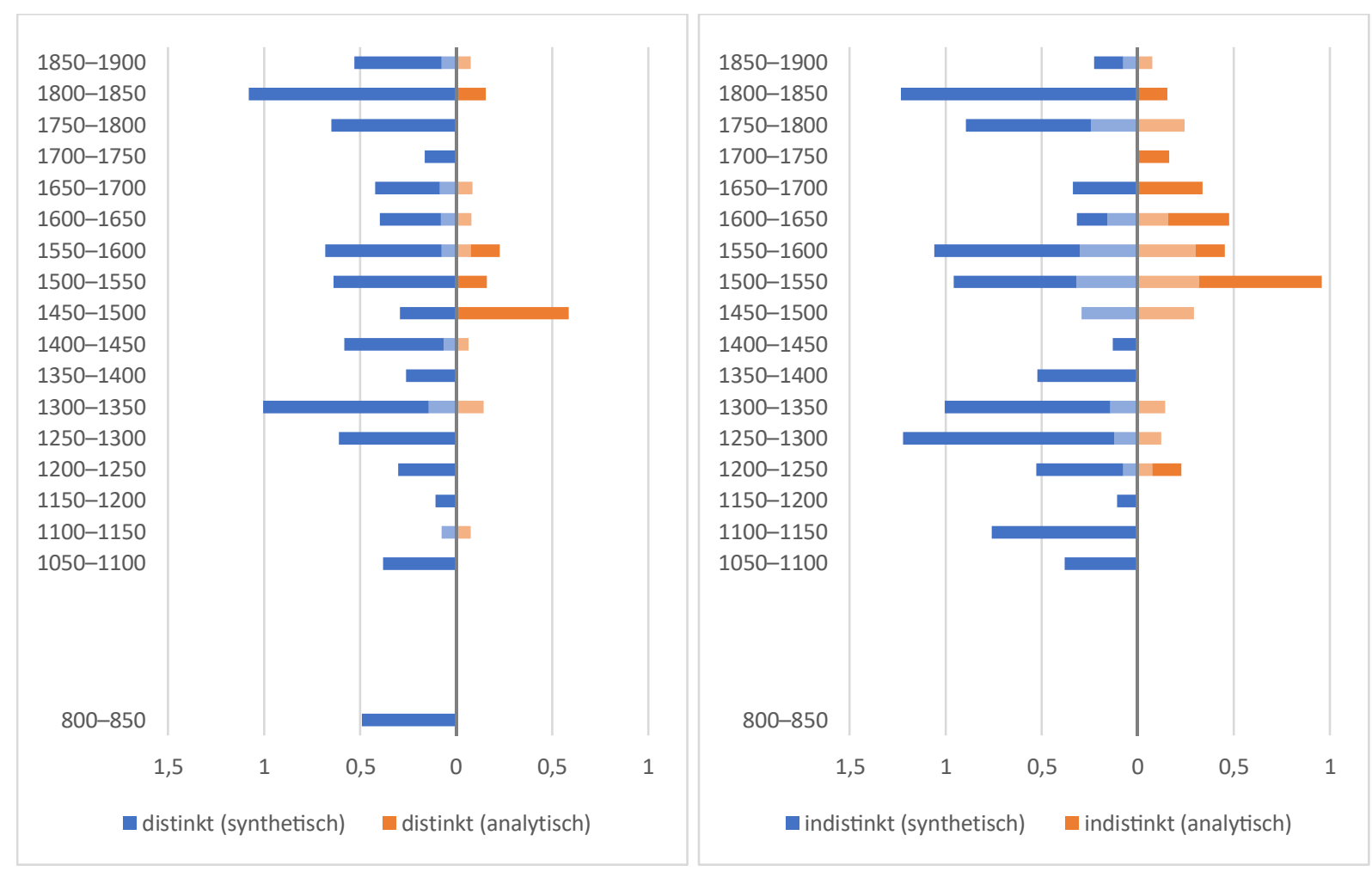

Abbildung 7: Synthetische (blau) und analytische Formen (orange) des Konjunktivs II von Verben mit distinkten (links; $N=55$ ) und indistinkten Formen des Konjunktivs II (rechts; $N=81$ ) in Konditionalsowie Vergleichssätzen (pro 1.000 Tokens).

Ein weiterer Grund für die Ausweitung analytischer Formen ist möglicherweise in Synkretismen im Bereich der Endungen zu suchen. Ursprünglich unterschieden sich Indikativ und Konjunktiv Präteritum im Singular starker Verben; durch Apokope fielen die Endungen der beiden Modi ab dem 13./14. Jahrhundert in der 1./3. Person zusammen (siehe Abbildung 8, links), so dass Unterscheidbarkeit nur mehr bei Stammalternanz gegeben war (i. e. nicht in Ablautreihen I und VII). Das konjunktivische -e wurde im 16. Jahrhundert recht bald wohl unter dem Einfluss ostmitteldeutscher Schriftlichkeit restituiert (cf. auch Reichmann/Wegera 1993: 245) und in der Folge mitunter auch an Indikativformen angehängt, was die dadurch erreichte Distinktheit der Formen wieder einebnete. Bei schwachen Verben trat Synkretismus zwischen Indikativ- und Konjunktivendungen bereits mit der Abschwächung in den Nebensilben zu Beginn des Mittelhochdeutschen ein. In diesem Bereich war eine Modusunterscheidung - außer bei rückumlautenden Verben - seit dieser Zeit flexivisch nicht mehr möglich. Dieser formseitige Zusammenfall scheint zunächst ohne Konsequenz gewesen zu sein (wenn er nicht für das Aufkommen der analytischen Formen relevant war), was darauf hindeutet, dass für die Markierung der Kategorie Konjunktiv II das Merkmal Präteritum bereits wichtiger war als das Merkmal Konjunktiv. Insofern wäre ein vollständiger Zusammenfall der beiden Modi im Präteritum - wie in anderen germanischen Sprachen ${ }^{33}$ - nicht überraschend gewesen, und im Wesentlichen ist dies auch die Situation in den späteren oberdeutschen Dialekten.

\footnotetext{
${ }^{33}$ Siehe die Situation in heutigen germanischen Sprachen wie Englisch oder Schwedisch (If I had time ..., Om jag hade tid ...).
} 
Problematischer und schwerwiegender war potenziell der Zusammenfall der Konjunktiv-IIFormen mit solchen des Präsens, wie er in der 3. Person Singular schwacher Verben durch Apokope eintreten konnte (z. B. machte $>$ macht), da durch ihn keine hinlängliche Unterscheidbarkeit zwischen Realis und Irrealis mehr gegeben ist. ${ }^{34}$ Sollte hier tatsächlich ein Zusammenhang mit der Ausbreitung analytischer Formen bestehen, wäre eine stärkere Tendenz zu analytischen Formen bei schwachen Verben zu erwarten, was jedoch nicht der Fall zu sein scheint (siehe Abbildung 6). Zudem kommt der Typ - $t$ im Korpus kaum vor (siehe Abbildung 8, rechts); stattdessen überwiegen (außer bei Modalverben etc.) ab dem 14. Jahrhundert ganz deutlich -ethaltige Formen, die sich von den mehrheitlich synkopierten Indikativ-Präsens-Formen unterschieden (cf. Fischer 2018: 338). Im 14. Jahrhundert sind somit vermutlich die Ursprünge des späteren bairischen Konjunktivmarkers - at zu suchen, ${ }^{35}$ der später auch auf starke Verben verallgemeinert wurde. ${ }^{36}$ In dieser Zeit begann auch der oberdeutsche Präteritumschwund, so dass von einer Festlegung des Typs -et auf den Konjunktiv II im Mündlichen dieser Zeit ausgegangen werden kann. ${ }^{37}$ Damit lag im Ostoberdeutschen seit dem 14. Jahrhundert auch bei schwachen Verben eine Präteritum- bzw. Konjunktiv-Markierung vor, die sie hinreichend von Präsens- bzw. Indikativformen unterschied. Um 1600 (etwa ein Jahrhundert nach der Restitution des - $e$ der starken Verben) wurde dieser Typ im Schriftlichen wieder durch das ältere -te ersetzt, während der Typ -et (als -at) dialektal fortbestand. Der potenziell fehlende Kontrast zu den Indikativformen des Präteritums war nur für das Schriftliche relevant, da diese mit dem Präteritumschwund für den mündlichen Sprachgebrauch ohnehin obsolet geworden waren. Fehlende Distinktheit der synthetischen Konjunktiv-II-Formen kann somit als Ursache für die Etablierung der Periphrase weitgehend ausgeschlossen werden.

\footnotetext{
${ }^{34}$ Eine analoge Begründung für den Präteritumschwund und das Ausweichen aufs Perfekt gilt mittlerweile als überholt (cf. Schrodt/Donhauser 2003: 2519; Fleischer/Schallert 2011: 132)

35 Die meines Wissens bisher ältesten Hinweise auf diese Form stammen aus dem Jahr 1407 (Schönbach 1899).

${ }^{36}$ Entsprechende „Mischformen“ starker Verben mit dem ursprünglich schwachen Konjunktivmarker -et/-at kommen im Korpus nicht vor. Allerdings gibt Auer (2009: 145-146) sechs Beispiele aus einem österreichischen Korpus des 18. Jahrhunderts wieder, u. a. aus Predigten, darunter entreissete, stoßete, befindete. Diese Fälle illustrieren, dass solche Formen vereinzelt durchaus in der ostoberdeutschen Schriftlichkeit auftreten konnten.

${ }^{37}$ So geht Dal (1960) davon aus, dass im ,,ausgehenden Mittelalter“ Präteritumschwund und Refunktionalisierung des Dentalsuffixes als Konjunktivmarker Hand in Hand gingen (cf. hierzu Nübling et al. 2017: 342; Fischer 2018: 343-347).
} 


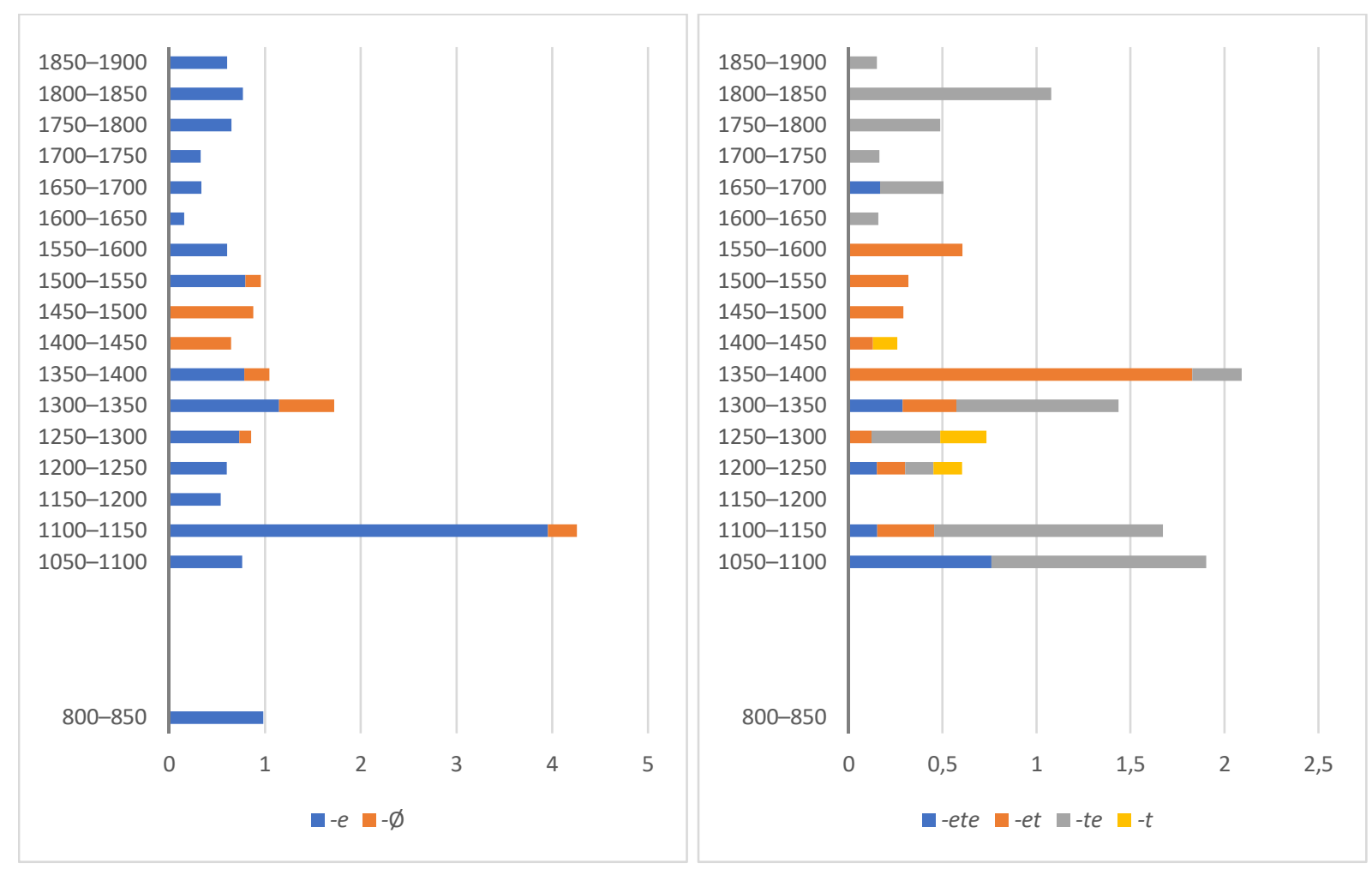

Abbildung 8: Endungsformen von starken (links, 1. und 3. Person Singular, $N=94$ ) und schwachen (rechts, 3. Person Singular, $N=64$ ) Formen des Konjunktivs II (pro 1.000 Tokens; inkl. Fälle mit abweichenden Vokalen, wie etwa -oti für -ete).

Da ein Effekt der mangelnden Distinktheit der synthetischen Konjunktiv-II-Formen damit wenig wahrscheinlich erscheint, ist möglicherweise zunächst weniger mit einem „Pull““- (im Sinn einer Vermeidungsstrategie) und eher mit einem „Push“-Effekt - ausgehend von der werdenbzw. würde-Konstruktion mit Infinitiv in anderer Funktion - zu rechnen. Die ursprüngliche inchoative bzw. ingressive Lesart dieser Periphrase ist in vielen der analytischen Beispiele aus dem Korpus noch gangbar und gerade in der Apodosis beinahe intrinsisch (Smirnova 2006, 2007), insofern man die Protasis als hypothetische Voraussetzung für das Eintreten (= Beginnen) der in der Apodosis formulierten Folge versteht. Die Grammatikalisierung dieser Konstruktion zuerst in der Apodosis und ihre anschließende analogische Ausbreitung auf weitere Kontexte ist nicht per se ungewöhnlich, wobei die Frage bestehen bleibt, wie sich diese innovative Form gegenüber etablierten Varianten durchsetzte.

Obwohl sich quantitativ keine entsprechende quantitative Tendenz nachweisen lässt, gibt es doch wohl zumindest aus synchroner Sicht einen weiteren Grund für die Ausbreitung der analytischen Konjunktivs-II-Variante, der mit der Unterscheidbarkeit zwischen Konjunktiv- und Indikativformen zu tun hat: Aus heutiger (schriftsprachlicher) Perspektive ist es bisweilen notwendig, die würde-Periphrase zu wählen, ${ }^{38}$ um den hypothetischen, nicht-vergangenheitsbezogenen Charakter einer Aussage klar zu markieren (cf. auch Breuer/Wittibschlager 2020: 142). ${ }^{39}$ Dieser Umstand macht die würde-Periphrase insgesamt - vor allem nach ihrer normativen

\footnotetext{
38 Wenngleich sie „noch heute von konservativer Stilkritik diskriminiert[...]“ wird (von Polenz 2021: 216).

39 So kann etwa der Satz Wenn er das machen würde, würde ich mich schämen kaum als *Wenn er das machte, schämte ich mich realisiert werden.
} 
„Freigabe“ in nicht-konditionalen Kontexten - zu einer flexibler einsetzbaren und „sichereren“ Variante als der synthetische Konjunktiv II (cf. auch Durrell 2007: 252f.), ${ }^{40}$ was auf längere Sicht zu ihrer Attraktivität beigetragen haben dürfte.

\section{$5 \quad$ Synthese}

Die diachrone Entwicklung des Konjunktivs II im Ostoberdeutschen wurde im Vorangehenden aus verschiedenen Blickwinkeln betrachtet. Die Ergebnisse sollen nun in einer Synthese zusammengeführt und unter Hinzuziehung weiterer Aspekte diskutiert werden.

Zunächst wurde gezeigt, dass die Herausbildung des (eigentlichen) Konjunktivs II als eigenständige modale Kategorie mit dem Verlust des funktionalen Tempusmerkmals der Konjunktiv-Präteritum-Form einherging. Der Zeitraum, in dem dies geschah, scheint aufgrund der quantitativen Verhältnisse sowie aufgrund der sonstigen Beleglage im Ostoberdeutschen nicht vor dem 11. Jahrhundert abgeschlossen gewesen zu sein - und damit deutlich später als bislang angenommen (siehe Kapitel 4.1). ${ }^{41}$ Bei diesem Befund spielt eine entscheidende Rolle die Tatsache, dass die meisten der vermeintlichen frühen Belege für einen tempusneutralen Gebrauch des Konjunktivs Präteritum aus der Literatur lateinische (oder im Fall des Gotischen griechische) Vergangenheitstempora wiedergeben und damit nicht als verlässliche Evidenz betrachtet werden können (cf. Fleischer/Schallert 2011: 44f.). Dies wirft die wichtige Frage auf, ob die Entstehung des Konjunktivs II - besonders in der Funktionsgruppe 1, i. e. als Irrealis/Potenzialis - eine Folge lateinischen Einflusses war oder ob sie durch ihn nur früher sichtbar geworden ist (siehe Fn. 19), die hier freilich nicht beantwortet werden kann. Jedenfalls erscheint es nicht ausgeschlossen, dass Sprachkontakt mit Latein auch zum Auftreten vergleichbarer Verwendungsweisen von (ursprünglichen) Vergangenheitsformen in anderen germanischen Sprachen beigetragen haben könnte, sodass ein gemeinsamer vorgeschichtlicher Ursprung dieses Gebrauchs nicht zwingend erscheinen muss (cf. auch Fn. 16).

Auch wenn die Entstehung des Konjunktivs II durch den Wegfall seiner temporalen Funktion gekennzeichnet ist, ist seine weitere Entwicklung offenbar maßgeblich von Entwicklungen im Bereich des Tempus geprägt. So machte zunächst das Aufkommen analytischer Tempusformen, allen voran des Perfekts, die Markierung zeitlicher Verhältnisse bei Konjunktiv-II-Formen wieder möglich, was die paradigmatische Sonderstellung des Konjunktivs II (jedenfalls in der Funktionsgruppe 1) als tempusindifferente Kategorie beseitigte, Symmetrie im Paradigma teilweise wiederherstellte und die neue präsentische Verwendung des ehemaligen Konjunktivs Präteritum festigte. Der Präteritumschwund, der im Oberdeutschen seit dem 14. Jahrhundert greifbar wird und ebenfalls mit der Etablierung analytischer Tempusformen in Verbindung stand, hatte in verschiedenerlei Hinsicht potenzielle Auswirkungen auf die weitere Entwicklung dieser neuen modalen Kategorie. Zunächst wurden mit dem Schwund des Präteritums als Vergangenheitstempus letzte Reste präteritaler Verwendungsweisen des eigentlichen Konjunktivs II im gesprochenen Oberdeutschen obsolet und seine präsentische Verwendungsweise

\footnotetext{
40 Elspaß (2005: 249) zufolge wurden in Briefen des 19. Jahrhunderts „,besonders Konj. II-Formen unregelmäßiger Verben“" gemieden.

${ }^{41}$ Beim uneigentlichen Konjunktiv II bestand noch länger - jedenfalls bis ca. 1400 - eine (passive) Tempusopposition.
} 
endgültig besiegelt. Praktisch gleichzeitig erschienen die ersten Fälle präsentischer Verwendungsweisen in der Funktionsgruppe 2 (i. e. in indirekter und finaler Verwendungsweise), in der der Konjunktiv bis dahin seine Tempusdifferenz bewahrt hatte - ein weiterer Hinweis auf die Auflösung des Präteritums als temporaler Kategorie. Die Langzeitfolge davon ist die weitgehende Austauschbarkeit der Tempora in der Funktionsgruppe 2 (cf. Dal 2004: 160) bzw. die heute herrschende Festlegung des Konjunktivs I auf diese Funktionsgruppe und die Reduktion des Konjunktivs II auf eine bloße Ausweichfunktion in diesem Bereich. Der beinahe vollständige (vorübergehende) Rückgang beider Funktionen des uneigentlichen Konjunktivs II (i. e. der Funktionsgruppe 2) im 16. Jahrhundert dürfte die Aufgabe des Konjunktivs in diesen Funktionen im Gesprochenen reflektieren. Das Wiederaufleben des Konjunktivs in beiden Funktionsgruppen seit dem 17. Jahrhundert steht wohl im Zusammenhang mit seiner normativen Behandlung in Grammatiken (siehe Kapitel 4.1 und 4.2). Die Funktionsgruppe 2 zeigt ab hier bereits deutlich die Neutralisation der Tempusunterscheidung.

Die temporale Verwendung des Indikativs Präteritum ist in geschriebenen oberdeutschen Quellen fortan ein Phänomen der Schriftlichkeit, das in der Folge auch stilistisch als schriftsprachlich markiert ist (cf. Pickl 2020c zur Polarisation zwischen Mündlichkeit und Schriftlichkeit, insbesondere in der Zeit um 1400) und keinen Rückhalt in der nativen, mündlichen Kompetenz mehr hat. Für den Konjunktiv Präteritum gilt dies nicht, wie etwa bis heute erhaltene starke Konjunktiv-II-Formen in den bairischen Dialekten zeigen. Auch die Refunktionalisierung und Ausweitung des ursprünglichen schwachen Präteritummarkers -et(e) als Konjunktiv-II-Marker -at weist in diese Richtung. Letztlich hatte im mündlichen Sprachgebrauch der Präteritumschwund das vollständige Aufgehen der ursprünglichen Tempusopposition in einer zweiteiligen, flexivisch realisierbaren Modusopposition - bei analytisch realisierten Vergangenheitstempora - zur Folge. Die formale Unterscheidung zwischen (Indikativ) Präsens und (Konjunktiv) Präteritum ist dabei rein historisch.

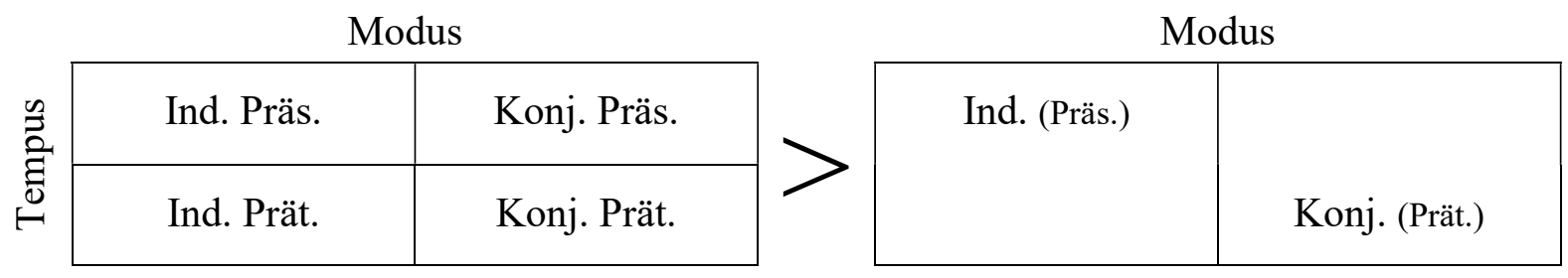

Tabelle 2: Entwicklung der synthetischen Tempus- und Moduskategorien im Ostoberdeutschen.

Im Gesprochenen entstand so eine Situation, in der Modus in der Regel morphologisch markiert wird und temporale Verhältnisse syntaktisch. Im Geschriebenen wurden freilich sowohl die Tempusdifferenz als auch die tempusinterne Modusdifferenz auch morphologisch - zusätzlich zu analytischen Formen - weiter tradiert, und zumindest in formaler Hinsicht besteht das viergliedrige Tempus-Modus-System (siehe Tabelle 2 links) im Schriftdeutschen bis zum heutigen Tag, wenngleich die Modusunterscheidung in funktionaler Hinsicht als dreigliedrig erscheint (Indikativ : Konjunktiv I : Konjunktiv II). ${ }^{42}$ Die graduelle Etablierung der neuen, rein modalen Funktion des ehemaligen Konjunktivs Präteritum zeigt sich in den Quellen auch quantitativ: So ist bis ins späte 15. Jahrhundert eine praktisch kontinuierliche Zunahme der Frequenz

\footnotetext{
42 Cf. Donhauser (1992: 240-241) für eine entsprechende Kontrastierung des bairischen mit dem standarddeutschen System.
} 
entsprechender Fälle festzustellen, was auf ihren zunehmenden Ausbau und ihre Festigung als funktionale Kategorie hindeuten könnte. Der darauffolgende stetige Rückgang, der bis ca. 1750 andauerte, und der plötzliche Anstieg danach sind vor diesem Hintergrund überraschend. Ein Vergleich mit den Zahlen aus Auers (2009) Zeitungskorpus (1650-1800) deutet darauf hin, dass es sich hier möglicherweise um ein textsortenspezifisches Phänomen handeln könnte. ${ }^{43}$

Die Vermutung, dass auch das Aufkommen der periphrastischen Form des Konjunktivs II im Zusammenhang mit dem Präteritumschwund - und der damit einhergehenden Unsicherheit bei der Bildung präteritaler Formen (cf. auch Auer 2022) - stehen könnte, hat sich mit den vorliegenden Daten hingegen nicht erhärten lassen. Auch fehlende Distinktheit der Konjunktiv-IIFormen scheint keine entscheidende Rolle bei seiner Herausbildung gespielt zu haben; damit verliert diese schon durch Szatzker (2002) und Durrell/Whitt (2016) zweifelhaft gewordene, u. a. auf Behaghel (1924) zurückgehende Vermutung weiter an Stichhaltigkeit. Der Prozess der Grammatikalisierung der ursprünglich inchoativen bzw. ingressiven würde-Form als modale Konstruktion macht die Suche nach einer Motivation für ihr Aufkommen möglicherweise teils hinfällig. Dennoch kann vermutet werden, dass zumindest solche Fälle, in denen synthetische Formen des Konjunktivs II aufgrund seiner Beschränkungen ausgeschlossen sind (siehe Fn. 39), insgesamt zu seiner Attraktivität als ,sichere Option“ und damit zu seiner Ausbreitung beigetragen haben (wenngleich dies keine Erklärung für seinen Gebrauch im gesprochenen Oberdeutschen ist, denn hier sind praktisch alle synthetischen Konjunktivformen klar vom Infinitiv zu unterscheiden). Jedoch ist der analytische Konjunktiv II auch im Kontext anderer periphrastischer Formen zu sehen: Möglicherweise macht sich hier eine Tendenz bemerkbar, den Tempus-Modus-Komplex zunehmend in die Syntax auszulagern und nur mehr Person und Numerus morphologisch zu markieren; auch in der Informationsstrukturierung mögen in bestimmten Kontexten Vorteile für eine analytische Lösung bestehen.

\section{$6 \quad$ Fazit und Ausblick}

Mit dem zeitlichen Umfang dieser Korpusuntersuchung war trotz der Beschränkung auf eine Textsorte ein einzigartiger Einblick in die diachrone Entwicklung des Konjunktivs II im Ostoberdeutschen möglich. Insbesondere wurde gezeigt, wie seine Etablierung als eigenständige modale Kategorie mit dem Verlust der temporalen Bedeutungskomponente des Konjunktivs Präteritum einherging und welche Rolle Entwicklungen im Bereich der Tempora, allen voran der Präteritumschwund und das Aufkommen analytischer Tempusformen, für seine funktionale und formale Entwicklung spielte. Im funktionalen Bereich betrifft dies u. a. die Herausbildung und bis heute bestehende Trennung der beiden in ihrer temporalen Funktionsweise verschiedenen Funktionsgruppen 1 und 2. Zudem waren trotz des schriftlichen Charakters der Datengrundlage Rückschlüsse auch auf das historische gesprochene Deutsch möglich. Im Bereich der Form des Konjunktivs II konnte gezeigt werden, dass die mit dem Präteritumschwund in Verbindung stehende Refunktionalisierung des ehemaligen Präteritummarkers -et(e) als Konjunktiv-II-Zeichen -at im gesprochenen Oberdeutschen im Rahmen der Reorganisation des alten

\footnotetext{
${ }^{43}$ Die Häufigkeit des Konjunktivs II in Auers (2009: 137-141) Korpus zeigt nicht - wie in den Predigten - einen Rückgang bis ca. 1750 und einen darauffolgenden starken Anstieg. Stattdessen entsprechen die Werte im ostoberdeutschen Teil ihres Korpus 7,4 (1650-1699), 4,8 (1700-1749) und 5,7 (1750-1799) Fällen pro 1.000 Tokens, regionenübergreifend 6,3, 7,2 bzw. 5,1 Fällen pro 1.000 Tokens.
} 
Tempus-Modus-Systems zu einer reinen Modusunterscheidung zu sehen ist. Hinsichtlich des Aufkommens analytischer Formen wurden verschiedene Hypothesen zu ihrer Etablierung erwogen, von denen keine bekräftigt werden konnte. Für die jüngere Zeit muss dennoch angenommen werden, dass Synkretismen im heutigen Deutsch die Verwendung analytischer Formen zumindest im Schriftlichen begünstigen. Für das gesprochenen Oberdeutsche kann ein solcher Effekt mithin nicht angenommen werden, da entsprechende Synkretismen hier nicht bestehen.

Verschiedene relevante Aspekte konnten in dieser Untersuchung nur in Ansätzen berücksichtigt werden. Dazu gehört in erster Linie die Textsortenvariation, die sich lediglich in Teilbereichen und für bestimmte Perioden im Vergleich mit anderen Studien (Auer 2009; Durrell/Whitt 2016) bis zu einem gewissen Grad einschätzen lässt. Hier wären weiterführende gezielte Studien, etwa auf der Basis von GerManC und/oder GermInnC, wünschenswert, um die Ergebnisse aus dem vorliegenden Beitrag besser einordnen zu können. Insbesondere könnte ein systematischer Vergleich mit mündlicheren Textsorten, insbesondere mit Briefen (Elspaß 2005), zur besseren Beurteilung des variativen Spektrums zwischen konzeptioneller Mündlichkeit und Schriftlichkeit und damit zu präziseren Erkenntnissen über den historischen mündlichen Sprachgebrauch beitragen. Damit in Zusammenhang steht die Frage nach dem stilistischen Status verschiedener Konjunktiv-II-Formen. Während heutige synthetische Bildungsweise schwachen Typs mit -at klar dialektal geprägt ist, kann für periphrastische Formen, v. a. mit würde, ${ }^{44}$ eine zeitweilige Assoziation mit dem Kanzleistil erwogen werden - eine Vermutung, die auch durch systematischere Textsortenvergleiche erhellen ließe -, bis sie nach dessen Aufgabe als Ideal spätestens im 19. Jahrhundert durch präskriptive Interventionen stigmatisiert wurden (cf. Durrell 2007). Die Rolle von Sprachbewusstsein, Standardisierung und Sprachkritik im Bereich des Konjunktivs II war bereits Gegenstand verschiedener Untersuchungen (z. B. Durrell 2007; Auer 2009; Brooks 2015); auch hier könnte noch gezielter zwischen innersprachlichen Entwicklungen und metasprachlichen Vorstellungen und Einlassungen abgeglichen werden, nicht nur um den Einfluss dieser Faktoren auf die Entwicklung des Konjunktivs II zu untersuchen, sondern auch um den Konjunktiv II und seine Formen und Verwendungsweisen besser in Sprachideologien einordnen zu können und seinen Stellenwert in ihnen zu verstehen. Schließlich haben sich an verschiedenen Stellen Parallelen zu anderen, v. a. germanischen, Sprachen gezeigt, die es sich lohnen würde weiter zu untersuchen. V. a. wäre es wichtig zu verstehen, ob auffallend parallele Entwicklungen, wie etwa Refunktionalisierung einer Präteritumform als präsentische Modalkategorie oder die Herausbildung und Verteilung analytischer Formen, in erster Linie das Ergebnis von Sprachverwandtschaft, Sprachkontakt, metasprachlichem Austausch oder allgemeiner standardsprachlicher Tendenzen (cf. Seiler 2019; Pickl 2020a) sind.

\section{Literaturverzeichnis}

Ágel, Vilmos (2000): „Syntax des Neuhochdeutschen bis zur Mitte des 20. Jahrhunderts“. In: Besch, Werner et al. (eds.): Sprachgeschichte. Ein Handbuch zur Geschichte der deutschen Sprache und ihrer Erforschung. Berlin/New York, de Gruyter: 1855-1903. (= Handbücher zur Sprach- und Kommunikationswissenschaft 2.2).

\footnotetext{
${ }^{44}$ Dies gilt explizit nicht für täte, das wohl seit jeher eine mündlich konnotierte Variante darstellte (siehe Kapitel 4.3).
} 
Auer, Anita (2009): The Subjunctive in the Age of Prescriptivism. English and German Developments during the Eighteenth Century. Basingstoke/New York: Palgrave Macmillan. (= Palgrave Studies in Language History and Language Change).

Auer, Anita (2022): „Die Verwendung des Konjunktivs II in den neudeutschen Komödien des oberdeutschen Benediktinermönchs Maurus Lindemayr (1723-1783)“. In: Havinga, Anna D./Lindner-Bornemann, Bettina (eds.): Deutscher Sprachgebrauch im 18. Jahrhundert. Sprachmentalität, Sprachwirklichkeit, Sprachreichtum. Heidelberg, Winter: 49-72. (= Germanistische Bibliothek 71).

Behaghel, Otto (1924): Deutsche Syntax. Eine geschichtliche Darstellung. Band II: Die Wortklassen und Wortformen. Heidelberg: Winter. (= Germanische Bibliothek, I. Abteilung: Sammlung germanischer Elementar- und Handbücher, I. Reihe: Grammatiken 10,2).

Behaghel, Otto (1928): Deutsche Syntax. Eine geschichtliche Darstellung. Band III: Die Satzgebilde. Heidelberg: Winter. (= Germanische Bibliothek, I. Abteilung: Sammlung germanischer Elementar- und Handbücher, I. Reihe: Grammatiken 10,3).

Breuer, Ludwig Maximilian/Wittibschlager, Anja (2020): „The variation of the subjunctive II in Austria. Evidence from urban and rural analyses“. Linguistic Variation 20/1: 136-171.

Brooks, Thomas (2015): ,,Diese bedingungslose Liebe zu den Sprachfehlern ...'. Sprachgeografische Betrachtungen zur würde-Umschreibung am Beispiel Robert Musil“. In: Lenz, Alexandra N./Glauninger, Manfred M. (eds.): Standarddeutsch im 21. Jahrhundert. Theoretische und empirische Ansätze mit einem Fokus auf Österreich. Wien, V\&R unipress: 237250.

Dal, Ingerid (1960): „Zur Frage des süddeutschen Präteritumschwunds“. In: Hartmann, Hans/ Neumann, Hans (eds.): Indogermanica. Festschrift für Wolfgang Krause zum 65. Geburtstag. Heidelberg, Winter: 1-7.

Dal, Ingerid (2014): Kurze deutsche Syntax auf historischer Grundlage. Berlin/Boston: de Gruyter. (= Sammlung kurzer Grammatiken germanischer Dialekte B, Ergänzungsreihe 7).

Demske, Ulrike (2019): „Zur Autonomie indirekter Redewiedergabe. Eine diachrone Perspektive“. Zeitschrift für Germanistische Linguistik 47/1: 70-101.

Donhauser, Karin (1992): „Der Konjunktiv im Bairischen“. In: Weiss, Andreas (ed.): Dialekte im Wandel: Referate der 4. Tagung zur bayerisch-österreichischen Dialektologie, Salzburg, 5. bis 7. Oktober 1989. Göppingen, Kümmerle: 226-242. (= Göppinger Arbeiten zur Germanistik 538).

Duden-Grammatik (2016), herausgegeben von Angelika Wöllstein und der Duden-Redaktion. Berlin: Dudenverlag. (= Duden Band 4).

Durrell, Martin (2007): ,,Deutsch ist eine würde-lose Sprache‘. On the history of a failed prescription“. In: Elspaß, Stephan et al. (eds.): Germanic Language Histories 'from Below' (1700-2000). Berlin/New York, de Gruyter: 243-258.

Durrell, Martin (2016): ,Textsortenspezifische und regionale Unterschiede bei der Standardisierung der deutschen Sprache“. In: Kwekkeboom, Sarah/Waldenberger, Sandra (eds.): PerspektivWechsel oder: Die Wiederentdeckung der Philologie. Band 1: Sprachdaten und Grundlagenforschung in der Historischen Linguistik. Berlin, Schmidt: 211-232.

Durrell, Martin (2017): „Zeitungssprache und Literatursprache bei der Ausbildung standardsprachlicher Normen im Deutschen im 17. und 18. Jahrhundert. Ein Vergleich anhand eines repräsentativen Korpus“. In: Pfefferkorn, Oliver/Riecke, Jörg/Schuster, Britt-Marie 
(eds.): Die Zeitung als Medium in der neueren Sprachgeschichte. Korpora-Analyse - Wirkung. Berlin/Boston, de Gruyter: 81-98. (= Lingua Historica Germanica 15).

Durrell, Martin/Whitt, Richard J. (2016): „The development of the würde + infinitive construction in Early Modern German (1650-1800)“. Beiträge zur Geschichte der deutschen Sprache und Literatur (PBB) 138/3: 325-364.

Elspaß, Stephan (2005): Sprachgeschichte von unten. Untersuchungen zum geschriebenen Alltagsdeutsch im 19. Jahrhundert. Tübingen: Niemeyer. (= Reihe Germanistische Linguistik 263).

Erdmann, Oskar (1874): Untersuchungen über die Syntax der Sprache Otfrids. Erster Teil: Die Formationen des Verbums in einfachen und in zusammengesetzten Sätzen. Halle: Waisenhaus.

Fischer, Hanna (2018): Präteritumschwund im Deutschen. Dokumentation und Erklärung eines Verdrängungsprozesses. Berlin/Boston: de Gruyter. (= Studia Linguistica Germanica 13).

Fleischer, Jürg (2008): „Zur Methodologie althochdeutscher Syntaxforschung“. Beiträge zur Geschichte der deutschen Sprache und Literatur (PBB) 128/1: 25-69.

Fleischer, Jürg/Schallert, Oliver (2011): Historische Syntax des Deutschen. Eine Einführung. Tübingen: Narr. (= Narr Studienbücher).

Furrer, Dieter (1971): Modusprobleme bei Notker. Die modalen Werte in den Nebensätzen der Consolatio-Übersetzung. Berlin/New York: de Gruyter. (= Das Althochdeutsche von St. Gallen. Texte und Untersuchungen zur sprachlichen Überlieferung St. Gallens vom 8. bis zum 12. Jahrhundert 2).

Hartweg, Frédéric/Wegera, Klaus-Peter (2005): Frühneuhochdeutsch. Eine Einführung in die deutsche Sprache des Spätmittelalters und der frühen Neuzeit. Tübingen: Niemeyer. (=Germanistische Arbeitshefte 33).

Kempf, Luise (2020): „Verloren im Wandel der Textgestaltung. Funktionen, Grammatikalisierung und Schwund der -selb-Anadeiktika“. In: Pasques, Delphine/Wich-Reif, Claudia (eds.): Textkohärenz und Gesamtsatzstrukturen in der Geschichte der deutschen und französischen Sprache vom 8. bis zum 18. Jahrhundert. Akten zum internationalen Kongress an der Universität Paris-Sorbonne vom 15. bis 17. November 2018. Berlin, Weidler: 417-444. (= Berliner Sprachwissenschaftliche Studien 35).

Kempf, Luise (2021): „German so-relatives. Lost in grammatical, typological, and sociolinguistic change“". In: Kranich, Svenja/Breban, Tine (eds.): Lost in Change. Amsterdam, Benjamins: 291-331. (= Studies in Language Companion Series 218).

Klein, Thomas/Solms, Hans-Joachim/Wegera, Klaus-Peter (2018): Mittelhochdeutsche Grammatik. Teil II: Flexionsmorphologie. Band 1: Substantive, Adjektive, Pronomina. Berlin/Boston: de Gruyter.

Koch, Günter (2019): „Bairisch in Deutschland“. In: Herrgen, Joachim/Schmidt, Jürgen Erich (eds.): Sprache und Raum. Ein internationales Handbuch der Sprachvariation. Band 4: Deutsch. Berlin/Boston, de Gruyter: 279-318. (= Handbücher zur Sprach- und Kommunikationswissenschaft 30.4).

Kopf, Kristin (2019): „Von Korpus zu Korpus. Herausforderungen und Chancen diachron korpusübergreifenden Arbeitens“. In: Szczepaniak, Renata/Hartmann, Stefan/Dücker, Lisa (eds.): Historische Korpuslinguistik. Berlin/Boston, de Gruyter: 1-28. (= Jahrbuch für Germanistische Sprachgeschichte 10). 
Langer, Nils (2001): Linguistic Purism in Action. How Auxiliary tun was Stigmatized in Early New High German. Berlin/New York: de Gruyter. (= Studia Linguistica Germanica 60).

Leirbukt, Oddleif (2008): Untersuchungen zur temporalen Umfunktionierung des Konjunktivs II im heutigen Deutsch. Tübingen: Niemeyer. (=Linguistische Arbeiten 519).

Lenz, Alexandra N. (2019): „Bairisch und Alemannisch in Österreich“. In: Herrgen, Joachim/ Schmidt, Jürgen Erich (eds.): Sprache und Raum. Ein internationales Handbuch der Sprachvariation. Band 4: Deutsch. Berlin/Boston, de Gruyter: 318-363. (= Handbücher zur Sprach- und Kommunikationswissenschaft 30.4).

Lockwood, William Burley (1968): Historical German Syntax. Oxford: Clarendon.

Lötscher, Andreas (1991): „Der Konjunktiv II bei Modalverben und die Semantik des Konjunktiv II“. Sprachwissenschaft 16: 334-364.

Nübling, Damaris et al. (2017): Historische Sprachwissenschaft des Deutschen. Eine Einführung in die Prinzipien des Sprachwandels. Tübingen: Narr Francke Attempto. (= Narr Studienbücher).

Paul, Hermann (2007): Mittelhochdeutsche Grammatik. Tübingen: Niemeyer. (= Sammlung kurzer Grammatiken germanischer Dialekte A, Hauptreihe 2).

Petrova, Svetlana (2008): Die Interaktion von Tempus und Modus. Studien zur Entwicklungsgeschichte des deutschen Konjunktivs. Heidelberg: Winter. (= Germanistische Bibliothek 30).

Pickl, Simon (2017): „Neues zur Negation im Mittelhochdeutschen. Grammatikalisierung und Variation in oberdeutschen Predigten“. Beiträge zur Geschichte der deutschen Sprache und Literatur (PBB) 139/1: 1-46.

Pickl, Simon (2019): „Wandel und Variation der Genitivstellung in einem diachronen Predigten-Korpus. Eine epochenübergreifende Längsschnitt-Studie“. In: Szczepaniak, Renata/ Hartmann, Stefan/Dücker, Lisa (eds.): Historische Korpuslinguistik. Berlin/Boston, de Gruyter: 176-197. (= Jahrbuch für Germanistische Sprachgeschichte 10).

Pick1, Simon (2020a): „Factors of selection, standard universals, and the standardisation of German relativisers". Language Policy 19: 235-258.

Pickl, Simon (2020b): „Gesamtsatzstrukturen zwischen online- und offline-Verarbeitung. Syntaktische Progression und Regression am Beispiel historischer deutscher Predigten“. In: Pasques, Delphine/Wich-Reif, Claudia (eds.): Textkohärenz und Gesamtsatzstrukturen in der Geschichte der deutschen und französischen Sprache vom 8. bis zum 18. Jahrhundert. Akten zum internationalen Kongress an der Universität Paris-Sorbonne vom 15. bis 17. November 2018. Berlin, Weidler: 145-172. (=Berliner Sprachwissenschaftliche Studien 35).

Pickl, Simon (2020c): „Polarization and the emergence of a written marker. A diachronic corpus study of the adnominal genitive in German“. Journal of Germanic Linguistics 32/2: 145182.

Pickl, Simon (2022): „Am Schnittpunkt von Variation und Wandel. Das Genitivattribut im 18. Jahrhundert im synchronen und diachronen Vergleich“. In: Havinga, Anna D./Lindner-Bornemann, Bettina (eds.): Deutscher Sprachgebrauch im 18. Jahrhundert. Sprachmentalität, Sprachwirklichkeit, Sprachreichtum. Heidelberg, Winter: 167-190. (= Germanistische Bibliothek 71). 
Polenz, Peter von (2013): Deutsche Sprachgeschichte vom Spätmittelalter bis zur Gegenwart. Band II: 17. und 18. Jahrhundert. Bearbeitet von Claudine Moulin unter Mitarbeit von Dominic Harion. Berlin/Boston: de Gruyter.

Polenz, Peter von (2021): Deutsche Sprachgeschichte vom Spätmittelalter bis zur Gegenwart. Band I: Einführung Grundbegriffe 14. bis 16. Jahrhundert. Bearbeitet von Claudine Moulin unter Mitarbeit von Maria Backes und Natalia Filatkina. Berlin/Boston: de Gruyter.

Reichmann, Oskar/Wegera, Klaus-Peter (eds.) (1993): Frühneuhochdeutsche Grammatik. Tübingen: Niemeyer. (= Sammlung kurzer Grammatiken germanischer Dialekte A, Hauptreihe 12).

Schönbach, Anton (1899): „Ueber den conjunctiv praeteriti im bairisch-österreichischen“. Beiträge zur Geschichte der deutschen Sprache und Literatur (PBB) 24: 232-238.

Schönherr, Monika (2010): Modalität und Modalitätsausdrücke in althochdeutschen Bibeltexten. Eine korpusgestützte Analyse. Dissertation, Universität Würzburg. (= Würzburger elektronische sprachwissenschaftliche Arbeiten 7).

Schrodt, Richard (2004): Althochdeutsche Grammatik II: Syntax. Tübingen: Niemeyer. (= Sammlung kurzer Grammatiken germanischer Dialekte A, Hauptreihe 5/2).

Schrodt, Richard/Donhauser, Karin (2003): „Tempus, Aktionsart/Aspekt und Modus im Deutschen“. In: Besch, Werner et al. (eds.): Sprachgeschichte. Ein Handbuch zur Geschichte der deutschen Sprache und ihrer Erforschung. Berlin/New York, de Gruyter: 2504-2525. (= Handbücher zur Sprach- und Kommunikationswissenschaft 2.3).

Seiler, Guido (2019): „Non-Standard Average European“. In: Nievergelt, Andreas/Rübekeil, Ludwig (eds.): , athe in palice, athe in anderu sumeunelicheru stedi'. Raum und Sprache. Festschrift für Elvira Glaser zum 65. Geburtstag. Heidelberg, Winter: 541-554. (= Germanistische Bibliothek 66).

Smirnova, Elena (2006): Die Entwicklung der Konstruktion würde + Infinitiv im Deutschen. Eine funktional-semantische Analyse unter besonderer Berücksichtigung sprachhistorischer Aspekte. Berlin/New York: de Gruyter. (= Studia Linguistica Germanica 82).

Smirnova, Elena (2007): „Rekonstruktion eines Grammatikalisierungsprozesses. Entwicklung der Konstruktion würde + Infinitiv zum Konjunktiv II-Grammem“. Zeitschrift für Dialektologie und Linguistik 74/1: 20-37.

Szatzker, Szilvia (2002): Zur Grammatikalisierung von werden/würde + Infinitiv im Neuhochdeutschen (1650-2000). Dissertation, Universität Budapest.

Thieroff, Rolf (2010): „Mood in German“. In: Rothstein, Björn/Thieroff, Rolf (eds.): Mood in the Languages of Europe. Amsterdam/Philadelphia, Benjamins: 133-154. (= Studies in Language Companion Series 120).

Valentin, Paul (1990): „Ausdrucksseite und Inhaltsseite in der Entwicklung des deutschen Modussystems“. In: Besch, Werner (ed.): Deutsche Sprachgeschichte. Grundlagen, Methoden, Perspektiven. Festschrift für Johannes Erben zum 65. Geburtstag. Frankfurt a. M. etc., Lang: 363-369.

Valentin, Paul (1997): „Der Modusgegensatz im Althochdeutschen“. In: Desportes, Yvon (ed.): Semantik der syntaktischen Beziehungen. Akten des Pariser Kolloquiums zur Erforschung des Althochdeutschen 1994. Heidelberg, Winter: 186-199. (= Germanische Bibliothek 27).

Welke, Klaus (2005): Tempus im Deutschen. Rekonstruktion eines semantischen Systems. Berlin/New York: de Gruyter. (= Linguistik-Impulse \& Tendenzen 13). 
Wunderli, Peter (1975): Modus und Tempus. Beiträge zur synchronischen und diachronischen Morphosyntax der romanischen Sprachen. Tübingen: Narr. (= Tübinger Beiträge zur Linguistik 62).

\section{Korpora}

GerManC = Durrell, Martin et al. (2012): GerManC. Oxford Text Archive. hdl.handle.net/20.500.12024/2544 [29.01.2022].

GermInnC $=$ Niehaus, Konstantin (2019): German Innsbruck Corpus (GermInnC). A Digital Corpus on Variation in German 1800-1950. doi.org/10.5281/zenodo.3457917

SermonC = Pickl, Simon (i. V.): SermonC. A Diachronic Corpus of Historical German Sermons. 